\title{
Auto-Ignition of Iso-Stoichiometric Blends of Gasoline-Ethanol-Methanol (GEM) in SI, HCCI and CI Combustion Modes
}

\section{Muhammad Waqas, Nimal Naser, and Mani Sarathy}

King Abdullah University of Science and Technology

\section{Jeroen Feijs}

Eindhoven University of Technology

\section{Kai Morganti}

Saudi Aramco

\section{Gustav Nyrenstedt and Bengt Johansson}

King Abdullah University of Science and Technology

CITATION: Waqas, M., Naser, N., Sarathy, M., Feijs, J. et al., "Auto-Ignition of Iso-Stoichiometric Blends of Gasoline-EthanolMethanol (GEM) in SI, HCCI and CI Combustion Modes," SAE Technical Paper 2017-01-0726, 2017, doi:10.4271/2017-01-0726.

Copyright (C) 2017 SAE International

\begin{abstract}
Gasoline-ethanol-methanol (GEM) blends, with constant stoichiometric air-to-fuel ratio (iso-stoichiometric blending rule) and equivalent to binary gasoline-ethanol blends (E2, E5, E10 and E15 in $\%$ vol.), were defined to investigate the effect of methanol and combined mixtures of ethanol and methanol when blended with three FACE (Fuels for Advanced Combustion Engines) Gasolines, I, J and A corresponding to RON 70.2, 73.8 and 83.9, respectively, and their corresponding Primary Reference Fuels (PRFs). A Cooperative Fuel Research (CFR) engine was used under Spark Ignition and Homogeneous Charge Compression Ignited modes. An ignition quality tester was utilized in the Compression Ignition mode. One of the promising properties of GEM blends, which are derived using the iso-stoichiometric blending rule, is that they maintain a constant octane number, which has led to the introduction of methanol as a drop-in fuel to supplement bio-derived ethanol. A constant RON/ HCCI fuel number/derived Research octane number property was observed in all three combustion modes for high RON fuels, but for low RON fuels, the iso-stoichiometric blending rule for constant octane number did not appear to be valid. The chemical composition and octane number of the base fuel also influenced the behavior of the GEM blends under different conditions.
\end{abstract}

\section{Introduction}

Due to their high octane number, high heat of vaporization, and low carbon intensity which make it possible to achieve high compression ratios and thermal efficiency [1], alcohol-based fuels have been recognized as a viable option to reduce engine dependency on fossil fuels $[\underline{2}, \underline{3}]$. Two alcohol-based fuels, ethanol and methanol, have been found to be suitable for spark ignition engines [4]. Both have the advantage of miscibility with gasoline, allowing their use as fuel additives [ㄷ]. Ethanol and methanol have a Research octane numbers (RONs) of 108 and 108.6, respectively $[\underline{6}, \underline{7}]$; this is higher than gasoline, which is typically RON 92 to 97 []. Blended with gasoline, they help to enhance the octane number and heat of vaporization of the mixture, reducing the tendency for the engine to knock $[\underline{9}, \underline{10}]$. The high octane rating also increases compression ratios and boost levels, thereby enabling the specific fuel consumption to be reduced [11].

The oxygenated E85 gasoline blend ( $85 \%$ ethanol and 15\% gasoline) is offered in many gas stations in the U.S. [12]. Ethanol in its pure form (E100) has also been used in Brazil [12]. China uses more methanol as a transport fuel than any other country in the world [13]. Several gasoline-methanol blends, including M5, M10, M15, M85 and M100, have already been deployed in fuel stations throughout China [13]. In the European Union, light blends of gasoline-methanol are used and it is expected that mid-blends of up to $25 \%$ of methanol in gasoline could be used in flex-fuel vehicles in the future [13]. The biomass limit is one of the major constraints in the use of biofuels like ethanol and methanol [14]. Methanol is often preferred over ethanol as a biofuel mainly because of the number of alternative production resources for methanol, which can be produced from renewable energy sources such as gasification of wood, agricultural by-products and municipal waste, as well as fossil fuel feedstocks like coal and natural gas [15]. 
Apart from their use in spark ignition engines, ethanol and methanol have also been utilized in other engine combustion modes such as Homogeneous Charge Compression Ignition (HCCI) and Compression Ignition (CI) engine. Xie et al. investigated the effect of alcohols on HCCI combustion and exhaust emissions by using E0, E50, E100, M50 and M100 [드. This study found that methanol often performs well for $\mathrm{HCCI}$ combustion and can reduce $\mathrm{NO}_{\mathrm{x}}$ emissions to extremely low levels [16]. Ethanol-diesel and methanoldiesel blends have been used as an alternative to pure diesel in CI engines [17].

It has been found that the addition of ethanol and methanol to gasoline as a base fuel results in increased RON $[\underline{18}, \underline{19}]$. A small quantity of ethanol and methanol causes a great increase in the RON, but the effect is diminished for both at high concentrations, showing a non-linear response [7], [19], [20], [21]. Anderson et al. reported that an addition of $10 \%$ ethanol resulted in a significant increase in the RON of the blend [22]. For methanol, $5-15 \%$ by volume results in a large increase in the RON, but at high concentrations the RON begins to converge [19]. Base octane number and composition plays an important role in the RON response for both ethanol and methanol $[\underline{19}, \underline{22}, \underline{23}]$.

The miscibility of methanol in mixtures of gasoline and ethanol provides a possible solution for reducing the dependency on fossil fuels and promoting renewable ethanol and methanol in the form of ternary GEM blends $[\underline{15}, 24]$. Using the concept of ternary blends, it is possible to formulate any binary gasoline-ethanol blend as a ternary blend composed of gasoline, ethanol and methanol [25]. The stoichiometric air-to-fuel ratio of ternary GEM blends is kept constant with the employment of methanol and equivalent to the binary blend of gasoline and ethanol, hence these blends are termed iso-stoichiometric [15].

To illustrate this, Figure 1 shows two possible ternary GEM blends (G86.8E9.5M3.7, G87.5E4M7.5) which have been derived from the binary blend of E15 (gasoline 85\% volume, ethanol 15\% volume). Also shown is G89.5E0M10.5 (gasoline $89.5 \%$ volume, methanol $10.5 \%$ volume), which is a possible binary blend of gasolinemethanol, replacing E15. In Figure 1, the stoichiometric air-fuel ratio remains constant along the lines connecting the four blends. The colored blends (G89.5 E0 M10.5, G87.5 E4 M7.5, G86.8 E9.5 M3.7 and G85 E15 M0) represent one combination of GEM blends. Other three combinations are defined in the Table 4.

A study to investigate if nearly similar octane numbers existed for ternary GEM blends equivalent to E15 and E85 was conducted [26]. For E15 blend, experiments were performed and for E85, molar octane blending modelling was adopted [26]. This is due to standard ASTM methods not able to predict accurately the octane numbers with high alcohol concentrations [26]. The principal behind GEM blends is to replace the conventional fuels with more promising fuels without the need to update existing vehicle fuel infrastructure systems [27]. One of the useful properties of GEM blends is that the octane number remains constant across the entire GEM range for a fixed air-fuel ratio [14]. This was a hypothetical approach for the study in E15 and E85 GEM blends [26]. In ternary blends equivalent to the E15, a small difference in the octane number was observed as methanol concentration was increased for GEM blends with same air-fuel ratio [26]. This was also found to be true for ternary blends of
E85 [26]. Different gasolines with RON 75, 85 and 95 were used for E85 ternary blends, and, using blending molar rules, it was discovered that low RON gasoline resulted in a greater decrease, in RON as the methanol concentration was increased in the GEM blends [26].

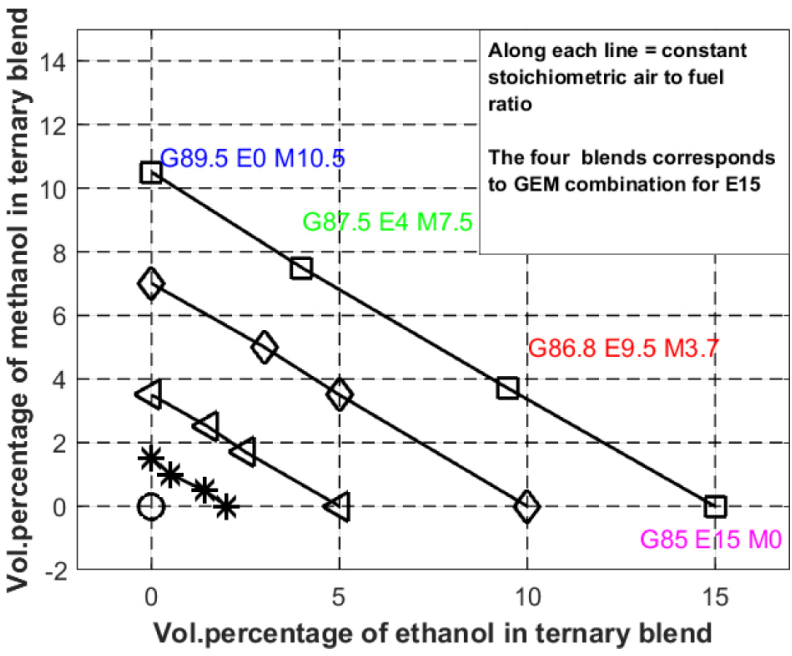

Figure 1. Four alternative GEM combinations with lines of constant stoichiometric air-fuel ratio

Another study was conducted to determine whether the ternary GEM blends may be used as drop-in fuels for spark ignited flex fuel engines $[\underline{15}, \underline{28}]$. The GEM blends equivalent to E85 were experimentally investigated and it was found that similar volumetric efficiency, knock behavior, brake specific fuel consumption (BSFC) and brake thermal efficiency (BTE) existed across all the equivalent ternary blends [15]. In another study, it was reported that GEM blends have constant octane numbers, constant volumetric energy content and nearly-constant enthalpy of vaporization $[\underline{14}, \underline{25}]$. Initial vehicle tests also reported that adopting GEM blends will not require recalibration of existing vehicles but can further reduce the amount of gasoline used, thereby providing energy security [14]. Different options for de-carbonizing transport vehicles were investigated in another study, promoting the use of tri-fuel vehicles capable of running at any combination of gasoline, ethanol and methanol [ㄷ]. Biomass limits, resulting in problems for producing biofuels, were discussed and alternate options, beyond the biomass limit, were proposed to promote the use of combinations of gasoline, ethanol and methanol at affordable prices [ $\underline{5}]$.

Collectively, previous studies have shown that alcohol based fuels could be a viable solution for transport vehicles providing an alternative to petroleum based fuels. Ethanol and Methanol having properties such as high octane number (109) and heat of vaporization four times higher than gasoline still make them attractive for spark ignition engines [9]. The use of ethanol is constrained by the biomass limit but the miscibility of methanol into a mixture of ethanol/ gasoline and its production at cheaper cost has led to the introduction of alternative ternary blended fuels $[\underline{14}, \underline{25}, \underline{29}]$. The tri-fuel combination of gasoline, ethanol and methanol is termed as GEM fuels. There is a hypothesis that by maintaining same stoichiometric air to fuel ratio for the mixtures of gasoline and alcohols, similar auto-ignition quality is observed [25]. This is called Isostoichiometric blending rule. 
Less is known about the performance of ternary GEM blends in alternative combustion modes such as HCCI and CI and most of the studies focused on spark ignition combustion modes [14, $\underline{15}, \underline{25}, \underline{26}]$. Mostly limited number of binary gasoline/ethanol mixtures has been investigated such as E85 or E15. This study therefore extends the iso-stoichiometric blending rule to a range of low, medium and higher alcohol (ethanol and methanol) concentrations. The hypothesis was validated by adding ethanol, methanol and mixtures of two to both FACE Gasolines and PRFs. The tests will be carried out in three different combustion modes; spark ignition combustion mode, HCCI mode; for which four HCCI numbers will be defined and in the diesel like combustion mode. The role of base fuel composition and its octane number on the octane enhancement behavior of GEM blends is also investigated.

\section{Experimental Set up}

A Waukesha Cooperative Fuel Research (CFR) engine was used for experiments in the SI and HCCI modes. The compression ratio in the engine can be varied from 4:1 to $15.5: 1$ with a resolution of 0.1 . The standard CFR engine is capable of operating at compression ratios of up to $18: 1$. This was not possible on the CFR engine used in this study, due to previous hardware modifications. Figure 2 shows the CFR engine used for the experiments. A port fuel injection system (PFI) was installed by replacing the carburetor. An Elster mass flow meter measured the intake air flow. $3.5 \mathrm{~cm}$ upstream of the fuel injector, the intake air temperature was measured with a thermocouple. Three ceramic heating clamps of $400 \mathrm{~W}$ each were used to change the intake air temperature. The equivalence ratio was measured with an ETAS lambda sensor; and pressurized helium gas was used to inject the fuel into the hot intake air with a feed fuel pressure at 6 bar. An AVL GH14 D pressure transducer, mounted on the cylinder, measured in-cylinder pressure. The water temperature was $95^{\circ} \mathrm{C}$.

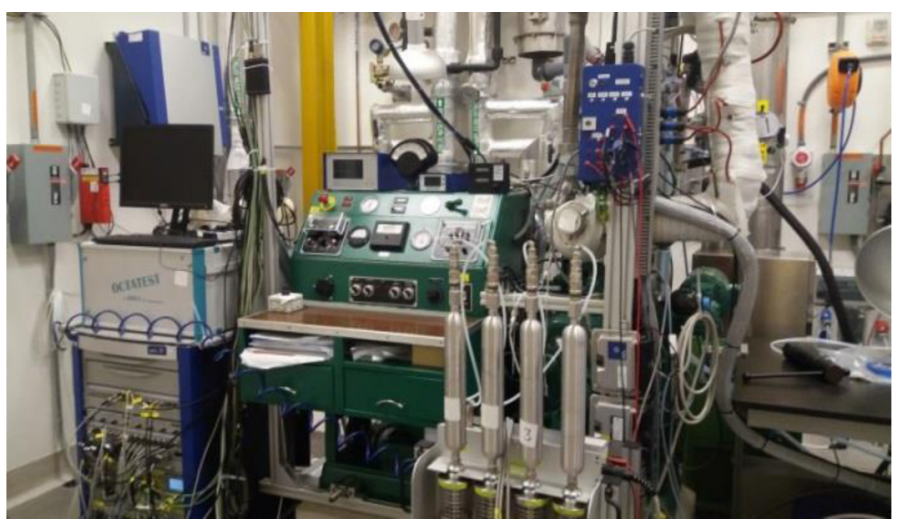

Figure 2. Cooperative Fuel Research engine (CFR)

The CFR was operated at RON conditions corresponding to an engine speed of $600 \mathrm{rpm}$, air inlet temperature of $52{ }^{\circ} \mathrm{C}$ and spark timing (ST) of -13 CAD (crank angle degree) for SI combustion mode. The four operating conditions for HCCI mode are listed in Table 1.

For comparison with SI conditions of RON and MON, HCCI-1 (600 $\left.\mathrm{rpm}, 52^{\circ} \mathrm{C}\right)$ and HCCI-4 $\left(900 \mathrm{rpm}, 149^{\circ} \mathrm{C}\right)$ were chosen. This included simultaneously changing two variables (speed and temperature). To investigate the effect of changing each variable individually, the other two HCCI numbers were selected; in total, four HCCI numbers were obtained. The selection of four HCCI numbers was supported by the work of Truedsson et al. [30].

Table 1. Four HCCI fuel numbers

\begin{tabular}{|l|l|l|}
\hline HCCI fuel numbers & Engine speed (rpm) & $\begin{array}{l}\text { Intake air } \\
\text { Temperature } \mathrm{T}_{\text {in }}\left({ }^{\circ} \mathrm{C}\right)\end{array}$ \\
\hline HCCI-1 (RON) & 600 & 52 \\
\hline HCCI-2 & 600 & 149 \\
\hline HCCI-3 & 900 & 52 \\
\hline HCCI-4 (MON) & 900 & 149 \\
\hline
\end{tabular}

Table 2 shows specifications and operating conditions for the CFR engine.

Table 2. Engine specifications and operating conditions

\begin{tabular}{|l|l|}
\hline Engine Type & Single cylinder CFR \\
\hline Injection System & Port fuel injection (PFI) \\
\hline Bore & $82.55 \mathrm{~mm}$ \\
\hline Stroke & $114.3 \mathrm{~mm}$ \\
\hline Connecting Rod & $254 \mathrm{~mm}$ \\
\hline Compression ratio & Variable from 4:1 to 15:1 \\
\hline Speed & $600-900$ rpm \\
\hline Spark timing (ST) & $-13 \mathrm{CAD}(\mathrm{Crank}$ Angle Degree) \\
\hline Minimum Intake Air Temperature & $52 \pm 2{ }^{\circ} \mathrm{C}$ \\
\hline Maximum Intake Air Temperature & $149 \pm 2{ }^{\circ} \mathrm{C}$ \\
\hline Lambda $(\lambda)$ & $1(\mathrm{SI})$ or $3(\mathrm{HCCI})$ \\
\hline
\end{tabular}

\section{IQT-Experiment}

The ignition quality of all the fuels used in the present work was determined with an ignition quality tester (IQT) from Advanced Engine Technology Ltd. in accordance with the ASTM D6890 standard [31]. The IQT is a constant volume combustion chamber with a volume of $0.21 \mathrm{~L}$, filled with zero-air with a composition of $20.9 \pm 1.0 \% \mathrm{O}_{2}$, the remaining $\mathrm{N}_{2}$ and trace amounts of hydrocarbons (Figure 3 ). The chamber was heated to a standard temperature with electric heaters. A liquid fuel spray was injected into the chamber with an inward-opening pintle nozzle [32]. The delay time between the start of injection i.e., the maximum of the needle lift and start of ignition was defined as the ignition delay time in the IQT. Note that the IQT is typically used to measure ignition delay of diesel-like fuels that have shorter time scales due to their higher reactivity compared to gasoline-like fuels. Because of the shorter time scales involved during diesel-like measurements in an IQT, low-temperature heat release (LTHR) was not apparent, which could be noticeable in certain gasoline-like fuels due to the longer time scales involved. The phenomenon of LTHR for some fuels has necessitated changes in the start of ignition definition from the conventional definition used by the IQT software. In the present method, ignition delay time -which is a combination of physical and chemical ignition delay time -was determined with the gradient

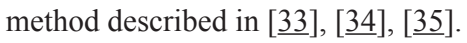




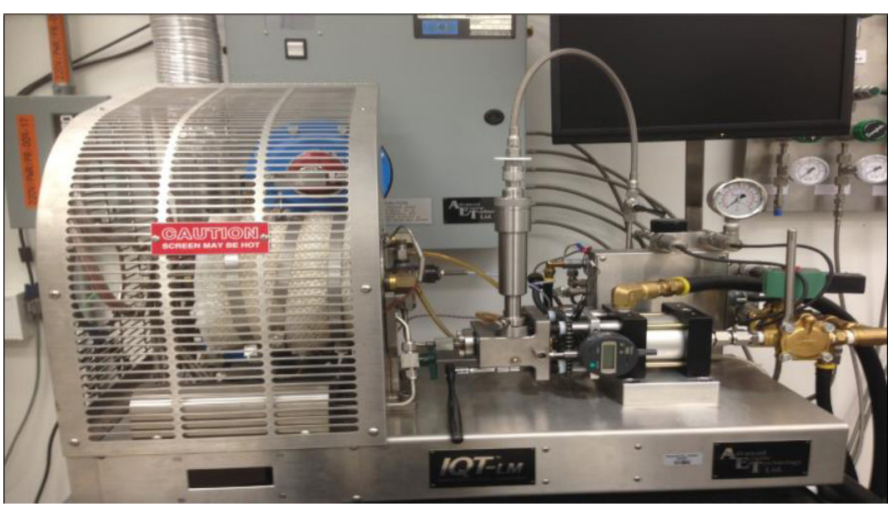

Figure 3. IQT apparatus

\section{Fuels and GEM Blends}

Three FACE Gasolines (FACE I, J, and A) were used for the experiments; composition and other properties of the FACE fuels are listed in the Table 3. For comparison purposes, PRF mixtures with RON 70 and 84 were also tested. Details about FACE gasolines can be obtained from the Coordinating Research Council [하]. Fundamental ignition and heat release characteristics of FACE

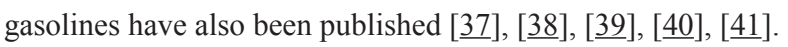

Table 3. FACE Fuels and their properties

\begin{tabular}{|l|l|l|l|l|l|}
\hline Fuel Classification & \multicolumn{3}{|l|}{ Low RON fuels } & \multicolumn{2}{l|}{ High RON fuels } \\
\hline Fuels & FACE I & $\begin{array}{l}\text { FACE } \\
\text { J }\end{array}$ & PRF 70 & FACE A & PRF 84 \\
\hline RON & 70.2 & 73.8 & 70 & 83.9 & 84 \\
\hline MON & 69.5 & 70.1 & 70 & 83.5 & 84 \\
\hline Sensitivity & 0.65 & 3.7 & 0 & 0.4 & 0 \\
\hline Aromatic (\%) & 1.15 & 31.69 & 0 & 0.38 & 0 \\
\hline N-Paraffin's (\%) & 14.39 & 31.64 & 30 & 11.65 & 16 \\
\hline
\end{tabular}

The effects of ethanol addition to the base fuels listed in Table 3 were investigated with the addition of ethanol addition at $0 \%, 2 \%, 5 \%$, $10 \%$, and $15 \%$ by volume [42].

\section{Ternary GEM Concept}

It is possible to formulate any ternary blend comprising gasoline, ethanol and methanol with the same stoichiometric air-fuel ratio, equivalent to the binary blend of gasoline and ethanol, according to the Ref. [25]. Using the iso-stoichiometric blending rule, a combination of four GEM blends was used for this study; for e.g. using one stoichiometric air-fuel ratio per ethanol concentration, three GEM blends were derived.

Table 4 provides an example of GEM blends with FACE I. The same blends were generated for FACE J, FACE A, PRF 70 and PRF 84. Four different combinations of GEM blends were found, corresponding to ethanol concentration by $2 \%, 5 \%, 10 \%$ and $15 \%$. For e.g. for the combination four (Cmb.4), G85 E15 M0 refers to gasoline with $85 \%$ volume, ethanol $15 \%$ volume and methanol $0 \%$. G86.8E9.5M3.7, G87.5E4M7.5 and G89.5E0M10.5 can be similarly defined. The four GEM blends corresponding to a combination have been defined as GE_, GEm, GeM and G_M. For GE_, only ethanol is blended with gasoline and for G_M, methanol is blended with gasoline. The other two GEM blends are referred as GEm and GeM. GEm refers to blends in which ethanol concentration is greater than methanol and for GeM methanol concentration is greater than ethanol. In PRF solutions, G is replaced by P70 or P84, depending on the PRF mixture octane number. For example P70Em refers to a mixture of PRF 70 with ethanol concentration greater than methanol. The missing GEM blends from the table are due to the miscibility problems of FACE I gasoline with methanol.

Table 4. Combination (Cmb.) of GEM blends for FACE I (numbers adjoining letters indicate volume percentage)

\begin{tabular}{|c|l|l|l|l|}
\hline $\begin{array}{c}\text { Cmb. } \\
(\mathrm{A} / \mathrm{F}) \mathrm{s}\end{array}$ & \multicolumn{1}{|c|}{ GE_ } & \multicolumn{1}{|c|}{ GEm } & GeM & G_M \\
\hline 1 & $\begin{array}{l}\text { G98E2M0 } \\
(14.99)\end{array}$ & $\begin{array}{l}\text { G98.1E1.4 M0.5 } \\
(14.98)\end{array}$ & $\begin{array}{l}\text { G98.5 E0.5M1 } \\
(15.00)\end{array}$ & $\begin{array}{l}\text { G98.5E0M1.5 } \\
(14.98)\end{array}$ \\
\hline 2 & $\begin{array}{l}\text { G95E5M0 } \\
(14.78)\end{array}$ & $\begin{array}{l}\text { G95.8E2.5M1.7 } \\
(14.78)\end{array}$ & $\begin{array}{l}\text { G96E1.5 M2.5 } \\
(14.77)\end{array}$ & $\begin{array}{l}\text { G96.5 E0M3.5 } \\
(14.78)\end{array}$ \\
\hline 3 & $\begin{array}{l}\text { G90E10M0 } \\
(14.43)\end{array}$ & $\begin{array}{l}\text { G91.5E5M3.5 } \\
(14.43)\end{array}$ & $\begin{array}{l}\text { G92E3M5 } \\
(14.42)\end{array}$ & $\begin{array}{l}\text { G93E0M7 } \\
(14.43)\end{array}$ \\
\hline 4 & $\begin{array}{l}\text { G85E15 M0 } \\
(14.09)\end{array}$ & $\begin{array}{l}\text { G86.8E9.5M3.7 } \\
(14.10)\end{array}$ & $\begin{array}{l}\text { G87.5E4M7.5 } \\
(14.11)\end{array}$ & \\
\hline
\end{tabular}

Note also that for any given GEM combination, methanol concentration increases as ethanol concentration decreases. For e.g. G85E15M0 shows maximum ethanol concentration whereas G89.5E0M10.5 shows maximum methanol concentration.

\section{Octane Number $(\mathrm{ON})$ of Blends}

\section{Research Octane Number}

The auto ignition properties of fuel in SI engines are characterized using RON and MON numbers [43]. The range of the scale for RON and MON lies between 0 to 100 . The two paraffinic hydrocarbons (iso-octane with a maximum value of 100 and n-heptane with a minimum value of 0 ) represent the range [ $\underline{43}]$. It is also possible to extend the range beyond 100 octane number, and this is achieved by extrapolating the scale by adding dilute tetraethyl lead (TEL) to iso-octane, based on an empirically determined relationship [44]. This allows the scale to be extended to 120.3 .

RON and MON are measured in a standardized single cylinder CFR engine using ASTM guideline tests $[\underline{44}, \underline{45}]$. The RON for this study is obtained by running the engine at $600 \mathrm{rpm}$ with inlet air temperature of $52^{\circ} \mathrm{C}$ and the spark timing of $13^{\circ}$ before top dead center (bTDC). Since the experimental set up has been modified with the introduction of port fuel injector, a transfer function is obtained by testing the PRFs with a RON range from 70 to 100 . The standard test of RON utilizes the similar engine which has been used for this study with the exception of carburetor which has been replaced by port fuel injector and also instead of using knock meter and detonation pickup for the detection of knock, in-cylinder pressure measurement are used to set knock criteria. Such changes possibly have very low effect on the obtained results of RON. The conversion procedure of the compression ratio readout to the mixture of PRF (iso-octane and n-heptane) is a definition of the transfer function for this study. A knocking criteria of peak to peak pressure fluctuations of 2 bar \pm 0.02 was selected to obtain the compression ratio. For all fuel 
blends, the compression ratio is increased until the criteria of peak-to-peak pressure of 2 bar is obtained. A lambda sweep was then performed to select the lambda, which gave maximum knock.

More details about the transfer function can be found in reference [42]. Figure 4 shows the transfer function obtained in reference and further used in this study [르].

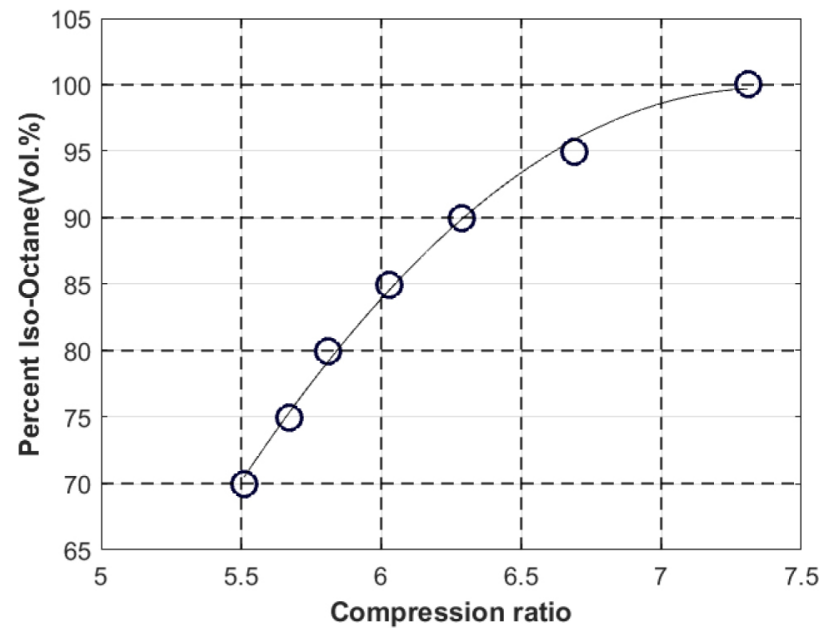

Figure 4. Transfer function in SI mode, $600 \mathrm{rpm}, 52^{\circ} \mathrm{C}, \mathrm{ST}=-13, \lambda=1[\underline{42}]$

A quadratic line of fit was obtained from Figure 4 and is given by:-

$$
R O N=x R_{C}^{2}+y R_{C}+z
$$

Where $R O N$ was defined as the percentage of iso-octane by volume in the PRF mixture and $R_{c}$ was the compression ratio. The values for the coefficients of the equation 1 are given in $\underline{\text { Appendix A in Table }}$

A1. The compression ratio for the tested fuel blends was used in equation 1 to obtain the RON.

\section{Homogeneous Charge Compression Ignition (HCCI) Fuel Number}

RON and MON cannot be directly used to characterize the autoignition behavior of fuels in the HCCI combustion mode [30]. A Lund-Chevron HCCI number was therefore developed for this purpose [밍. The HCCI fuel numbers can be obtained by determining the compression ratio for auto-ignition of the tested fuel with a CA50 (crank angle for $50 \%$ heat release) of $3^{\circ}$ aTDC. A transfer function was obtained for the HCCI combustion mode using mixtures of primary reference fuels (PRFs) as discussed in [42]. Figure 5 shows the transfer function obtained for all the four HCCI conditions [42].

A line of best fit was obtained for all four conditions. The line of best fit was in the form of quadratic equation given by:-

$$
\text { HCCI fuel number }=d R_{c}^{2}+e R_{c}+f
$$

Where the HCCI fuel number defined the percentage of iso-octane by volume in the PRF mixture and $R_{c}$ was the compression ratio. Values for the coefficients in equation 2 are given in Appendix A in Table A2. For each of the blends, the obtained compression ratio was used, along with equation 2 , to estimate the HCCI fuel number.

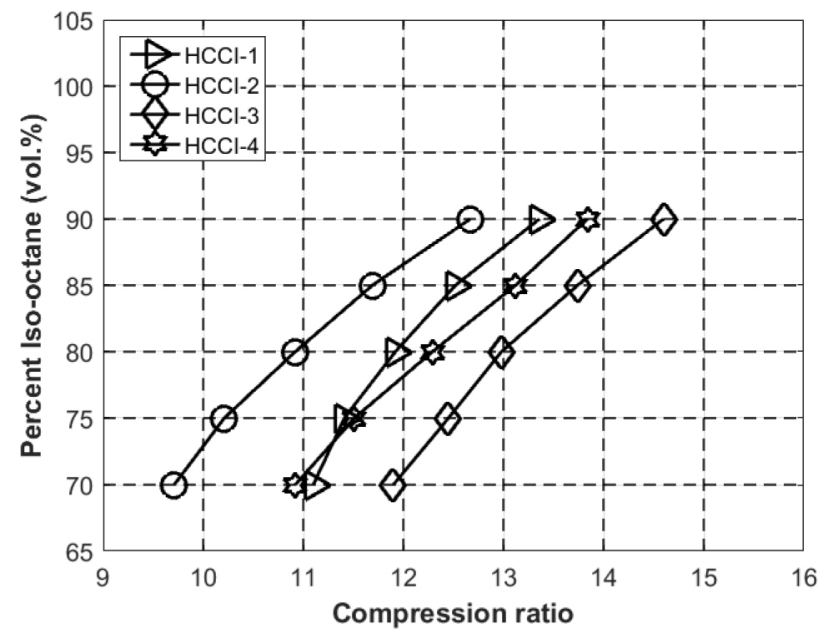

Figure 5. Transfer function in HCCI mode for four HCCI operating conditons, $\lambda=3[\underline{42}]$

\section{Derived Research Octane Number (DRON}

Ignition delays for the blends were obtained using the ignition quality tester (IQT). The derived cetane number (DCN) for the fuel blends was estimated using Equation 3, with the ignition delay range from 3.1 to $6.5 \mathrm{~ms}$, For values outside this range, Equation 4 was used [34].

$$
D C N=4.46+\left(\frac{186.6}{\tau_{i d}}\right)
$$

$$
D C N=83.99\left[\left(\tau_{i d}-1.512\right)^{-0.658}\right]+3.547
$$

Where $\tau_{i d}=$ Total ignition delay time

For comparison with HCCI and SI results, the estimated DCN was further converted to (DRON) given by [35]:

$$
D R O N=-293\left(\frac{D C N}{100}\right)^{2}-52\left(\frac{D C N}{100}\right)+114.1
$$

\section{Results}

Note that symbols such as GE_, GEm, GeM, etc. are used throughout the following section. Details on the definition of these symbols can be found in the Fuels and GEM blends section. For gasoline-ethanol (GE_), data has been taken from a previous publication of the author for comparison purposes [녀] .

Three FACE gasolines (FACE I, J and A) along with PRF 70 and PRF 84 were tested in the HCCI mode as base fuels. It was also emphasized that RON was not an ideal indicator of auto-ignition characteristics for the HCCI mode, therefore the HCCI number was obtained and will be used in the Results section. More information regarding the four HCCI numbers can be found in the Introduction and [42]. 
The first part of the result section will discuss HCCI results which will include a discussion about both high RON base fuels (FACE A and PRF 84) and low RON base fuels (FACE I, FACE J and PRF 70). Before discussing the results, tables representing the GEM blends tested for each of the base fuel will be presented. The missing GEM blends from the tables are due to the miscibility problems of the base fuel with methanol.

\section{HCCI Results}

\section{High RON Fuels}

Table 5 and $\underline{6}$ shows the GEM blends for PRF 84 and FACE A respectively. The term $\mathrm{G}$ represents the base fuel and has been defined in the caption of the tables. On the figures, the volume percentages shown on the far left corresponds to ethanol $(0 \%, 2 \%, 5 \%, 10 \%, 15 \%)$ whereas on the far right side belongs to methanol $(0 \%, 1.5 \%, 3.5 \%$, $7 \%$ ) obtained using iso-stoichiometric blending rule.

Table 5. Combination (Cmb.) of GEM blends for PRF 84 (G represents PRF 84 and numbers adjoining letters indicate volume percentage)

\begin{tabular}{|c|l|l|l|l|}
\hline $\begin{array}{c}\text { Cmb. } \\
(\mathrm{A} / \mathrm{F}) \mathrm{s}\end{array}$ & \multicolumn{1}{|c|}{ GE_ } & \multicolumn{1}{|c|}{ GEm } & GeM & G_M \\
\hline 1 & $\begin{array}{l}\text { G98E2M0 } \\
(14.99)\end{array}$ & $\begin{array}{l}\text { G98.1E1.4 M0.5 } \\
(14.98)\end{array}$ & $\begin{array}{l}\text { G98.5 E0.5M1 } \\
(15.00)\end{array}$ & $\begin{array}{l}\text { G98.5E0M1.5 } \\
(14.98)\end{array}$ \\
\hline 2 & $\begin{array}{l}\text { G95E5M0 } \\
(14.78)\end{array}$ & $\begin{array}{l}\text { G95.8E2.5M1.7 } \\
(14.78)\end{array}$ & $\begin{array}{l}\text { G96 E1.5M2.5 } \\
(14.77)\end{array}$ & $\begin{array}{l}\text { G96.5 E0M3.5 } \\
(14.78)\end{array}$ \\
\hline 3 & $\begin{array}{l}\text { G90E10M0 } \\
(14.43)\end{array}$ & $\begin{array}{l}\text { G91.5E5M3.5 } \\
(14.43)\end{array}$ & $\begin{array}{l}\text { G92E3M5 } \\
(14.42)\end{array}$ & - \\
\hline 4 & $\begin{array}{l}\text { G85E15 M0 } \\
(14.09)\end{array}$ & $\begin{array}{l}\text { G86.8E9.5M3.7 } \\
(14.10)\end{array}$ & $\begin{array}{l}\text { G87.5E4M7.5 } \\
(14.11)\end{array}$ & - \\
\hline
\end{tabular}

Table 6. Combination (Cmb.) of GEM blends for FACE A (G represents FACE A and numbers adjoining letters indicate volume percentage)

\begin{tabular}{|c|l|l|l|l|}
\hline $\begin{array}{c}\text { Cmb. } \\
(\mathrm{A} / \mathrm{F}) \mathrm{s}\end{array}$ & \multicolumn{1}{|c|}{ GE_ } & \multicolumn{1}{|c|}{ GEm } & GeM & G_M \\
\hline 1 & $\begin{array}{l}\text { G98E2M0 } \\
(14.99)\end{array}$ & $\begin{array}{l}\text { G98.1E1.4 M0.5 } \\
(14.98)\end{array}$ & $\begin{array}{l}\text { G98.5 E0.5M1 } \\
(15.00)\end{array}$ & $\begin{array}{l}\text { G98.5E0M1.5 } \\
(14.98)\end{array}$ \\
\hline 2 & $\begin{array}{l}\text { G95E5M0 } \\
(14.78)\end{array}$ & $\begin{array}{l}\text { G95.8E2.5M1.7 } \\
(14.78)\end{array}$ & $\begin{array}{l}\text { G96 E1.5M2.5 } \\
(14.77)\end{array}$ & $\begin{array}{l}\text { G96.5 E0M3.5 } \\
(14.78)\end{array}$ \\
\hline 3 & $\begin{array}{l}\text { G90E10M0 } \\
(14.43)\end{array}$ & $\begin{array}{l}\text { G91.5E5M3.5 } \\
(14.43)\end{array}$ & $\begin{array}{l}\text { G92E3M5 } \\
(14.42)\end{array}$ & $\begin{array}{l}\text { G93E0M7 } \\
(14.43)\end{array}$ \\
\hline 4 & $\begin{array}{l}\text { G85E15 M0 } \\
(14.09)\end{array}$ & $\begin{array}{l}\text { G86.8E9.5M3.7 } \\
(14.10)\end{array}$ & $\begin{array}{l}\text { G87.5E4M7.5 } \\
(14.11)\end{array}$ & - \\
\hline
\end{tabular}

Figure 6 shows the variation of the HCCI fuel number \#1 at an engine speed of $600 \mathrm{rpm}$ and inlet air temperature of $52^{\circ} \mathrm{C}$. The gray lines connecting the data points are only added to understand the data in a better way and make it easier for the readers. The base fuel used was PRF 84. Data points with same color code represent one combination of GEM blends. The terms GE_, GEm, GeM and G_M on x-axis have been defined in the Fuels and GEM blends section. The percentages labeled for GE_ and G_M show the variation of $\mathrm{HCCI}$ fuel number \#1, respectively, with increasing ethanol and methanol concentrations. For clarity, percentages of ethanol and methanol in GEm and GeM are not shown in the figure. For a 5\% GEM combination, a negative slope, showing a decrease in HCCI fuel number, is observed as ethanol is gradually replaced by methanol from P84E_to P84_M i.e. from left to right on $\mathrm{x}$-axis.

Figure 7 shows the variation of HCCI fuel number \# 2 with an increased inlet air temperature of $149^{\circ} \mathrm{C}$ for PRF 84 as the base fuel. The increased inlet air temperature shows no effect, with similar behavior for $5 / 3.5 \%$ and $2 / 1.5 \%$ mixtures. A saturation effect, with almost no additional increase in the octane number, is observed from $10 \%$ to $15 \%$. The same effect with low inlet air temperature could not be measured due to engine limitations - mainly a limited maximum compression ratio.

Figure 8 shows HCCI fuel number \#1 similar to RON conditions with FACE A as the base fuel. FACE A behaves much like PRF 84 (Fig. 6) but no slope for $5 / 3.5 \%$ is observed. A saturation effect is seen when doubling from 5 to $10 \%$, with little increase in HCCI fuel number \# 1 .

Figure 9 shows the effect of increasing the inlet air temperature to $149^{\circ} \mathrm{C}$ with FACE A as the base fuel. HCCI fuel number \# 2 behaved similarly to HCCI \# 1 (Fig. 8 ), but with more effect from the $10 \%$ ethanol. A saturation effect was found for $15 \%$ ethanol. A similar saturation effect was also observed for PRF 84 at engine speed of $600 \mathrm{rpm}$ and inlet air temperature of $149^{\circ} \mathrm{C}$.

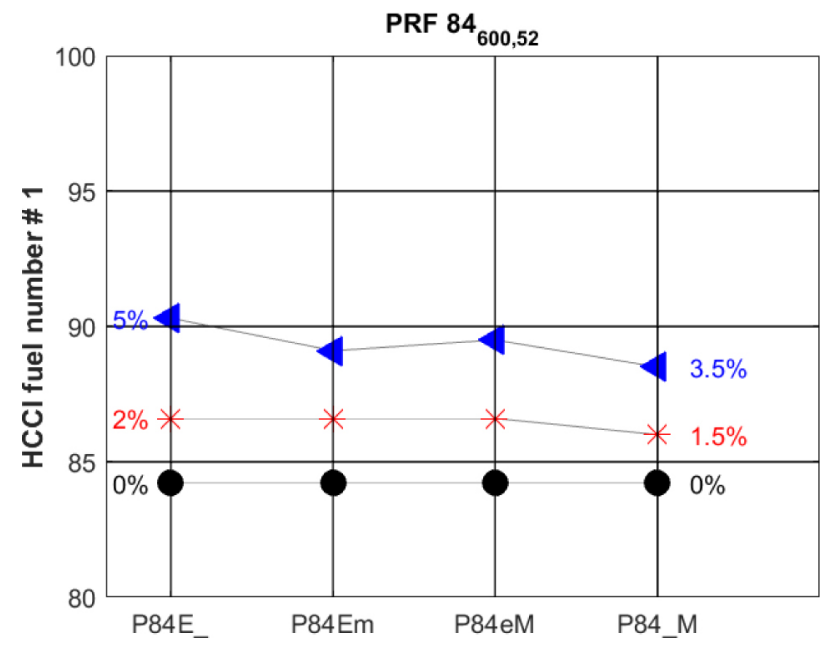

Figure 6. HCCI fuel number $\# 1$ at $600 \mathrm{rpm}, 52^{\circ} \mathrm{C}$ for PRF $84, \lambda=3$

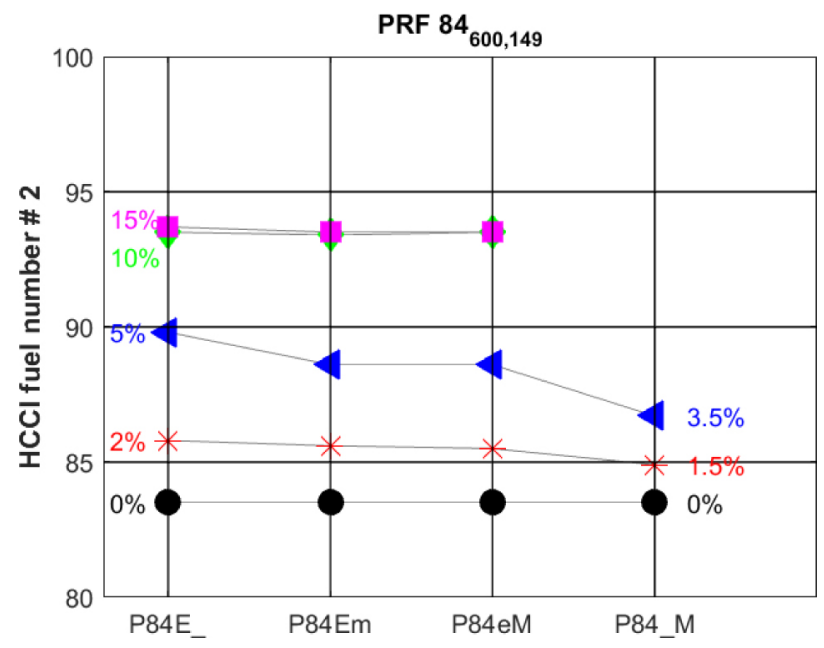

Figure 7. HCCI fuel number $\# 2$ at $600 \mathrm{rpm}, 149^{\circ} \mathrm{C}$ for PRF $84, \lambda=3$ 


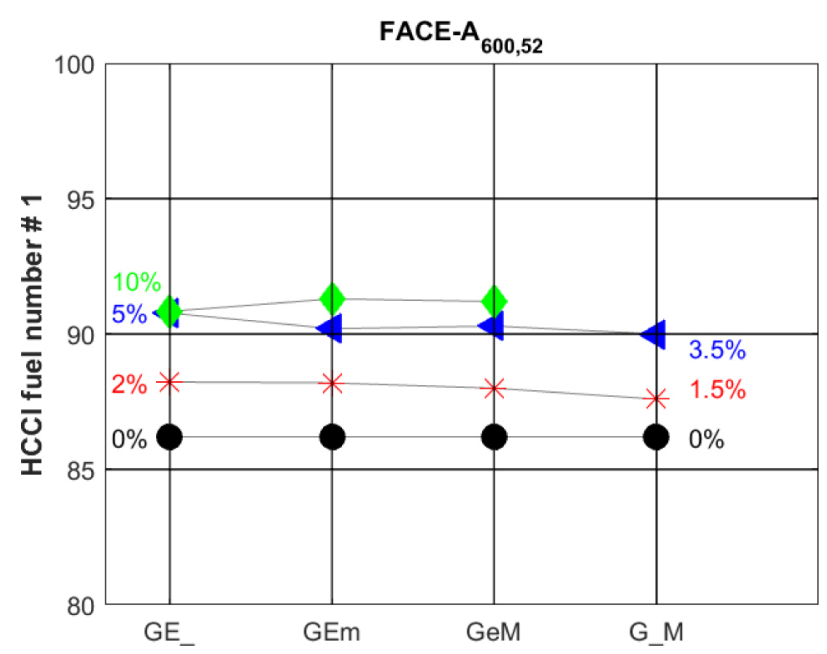

Figure 8. HCCI fuel number $\# 1$ at $600 \mathrm{rpm}, 52^{\circ} \mathrm{C}$ for FACE A, $\lambda=3$

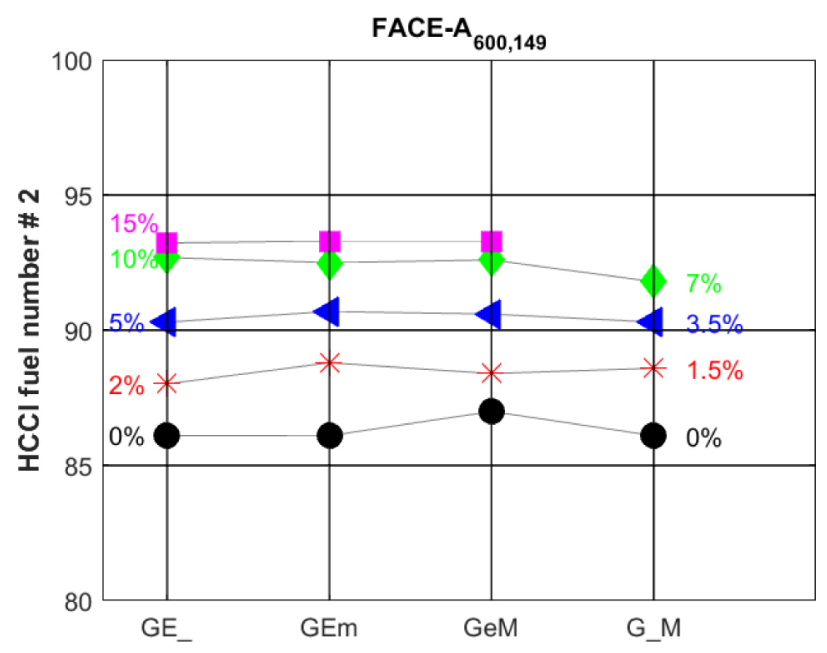

Figure 9. HCCI fuel number \# 2 at $600 \mathrm{rpm}, 149^{\circ} \mathrm{C}$ for FACE A, $\lambda=3$

Figure 10 shows the effect of engine speed only for PRF 84. No slope is observed and the results were quite similar to HCCI fuel number \# 1 (Fig.6). The horizontal lines for $2 \%$ and $5 \%$ indicate that the combined mixtures of ethanol and methanol were as effective as pure alcohols results in nearly similar octane numbers.

Figure 11 is the combined effect of speed and inlet air temperature. A larger effect of small concentration of alcohol was found, no clear slope, and a saturation effect is present.

Figure 12 shows the effect of engine speed only for FACE A. Higher HCCI fuel number than at $600 \mathrm{rpm}(\underline{\text { Fig. 8) }})$ is observed for all concentrations. The additional effect of alcohol is about the same with a small drop of HCCI fuel number for pure methanol case.

Figure 13 shows the combined effect of inlet air temperature and speed. In this condition the alcohols appears to be much less effective with less increase in the HCCI fuel number both for low and high concentrations. A saturation effect was observed for all the concentrations as expected because as the inlet temperature increases ethanol comparably becomes more reactive due to its high-octane sensitivity [41]. The higher sensitivity results in ethanol being less effective as octane improver as the inlet temperature and in-cylinder temperature increases.
Overall, the lines are horizontal and using the iso-stoichiometric blending rule, the octane enhancement was similar for ternary GEM blends for 84 RON fuels. FACE A and PRF 84 behaved similarly.

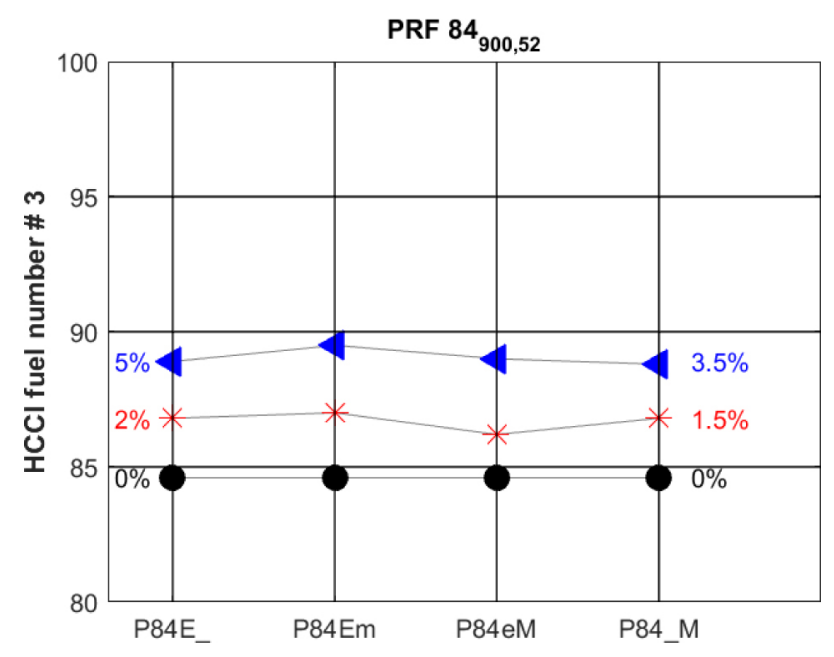

Figure 10. HCCI fuel number $\# 3$ at $900 \mathrm{rpm}, 52^{\circ} \mathrm{C}$ for PRF $84, \lambda=3$

Briefly, a saturation effect is observed at high ethanol/methanol concentrations for high RON fuels. The blending behavior of ethanol with gasoline still lacks a detailed fundamental understanding [7]. It has been found previously that for low ethanol concentrations, octane sensitivity of the blend increases significantly showing an important role of ethanol on the chemistry of the blend [7]. At higher concentrations of ethanol, the octane sensitivity becomes less dependent on ethanol content [7]. Other studies have also highlighted that a significant increase was observed in the RON for low ethanol concentrations, but this effect diminishes at high concentrations [ $[\underline{7}, \underline{22}$, $\underline{46}, 47]$. The same observation is seen in HCCI results showing that ethanol blending behaves similarly both in SI and HCCI conditions.

It was also observed for high RON fuels that with $3.5 \%$ methanol addition, similar HCCI numbers are obtained as that of corresponding $5 \%$ ethanol. It has been previously found that alcohols due to their high heat of vaporization compared to gasoline result in higher RON due to charge cooling effect $[\underline{19}, \underline{48}]$. The possible explanation for $3.5 \%$ methanol resulting in similar HCCI number could be due to higher heat of vaporization of methanol than ethanol [19]. Such observation was not found for the low RON fuel, which will be discussed in the next section, suggesting that base fuel octane number also has some role in the blending of gasoline and methanol.

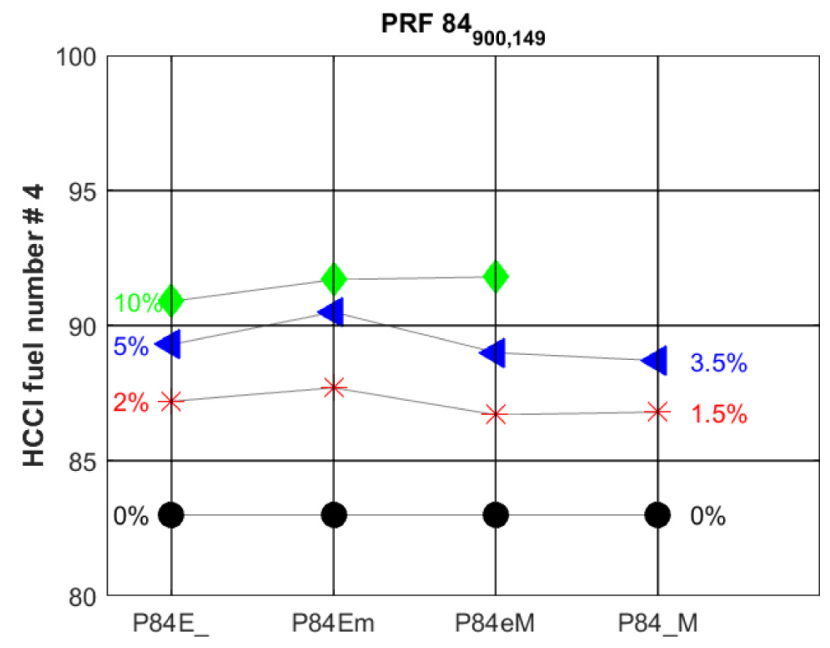

Figure 11. HCCI fuel number $\# 4$ at $900 \mathrm{rpm}, 149^{\circ} \mathrm{C}$ for PRF $84, \lambda=3$ 


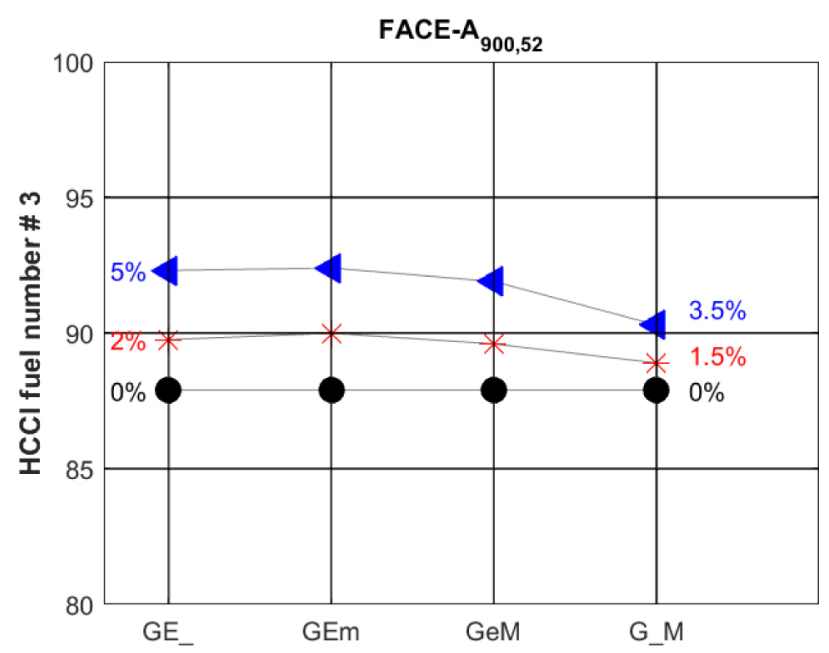

Figure 12. HCCI fuel number $\# 3$ at $900 \mathrm{rpm}, 52^{\circ} \mathrm{C}$ for FACE A, $\lambda=3$

\section{Low RON Fuels}

Tables $7, \underline{8}$ and $\underline{9}$ show the GEM blends for PRF 70 FACE I and FACE J respectively. Again, refer to the caption on the table to identify base fuel, which is represented by G.

Table 7. Combination (Cmb.) of GEM blends for PRF 70 (G represents PRF 70 and numbers adjoining letters indicate volume percentage)

\begin{tabular}{|c|l|l|l|l|}
\hline $\begin{array}{c}\text { Cmb. } \\
(\mathrm{A} / \mathrm{F}) \mathrm{s}\end{array}$ & \multicolumn{1}{|c|}{ GE } & \multicolumn{1}{|c|}{ GEm } & GeM & G_M \\
\hline 1 & $\begin{array}{l}\text { G98E2M0 } \\
(14.99)\end{array}$ & $\begin{array}{l}\text { G98.1E1.4 M0.5 } \\
(14.98)\end{array}$ & $\begin{array}{l}\text { G98.5 E0.5M1 } \\
(15.00)\end{array}$ & $\begin{array}{l}\text { G98.5E0M1.5 } \\
(14.98)\end{array}$ \\
\hline 2 & $\begin{array}{l}\text { G95E5M0 } \\
(14.78)\end{array}$ & $\begin{array}{l}\text { G95.8E2.5M1.7 } \\
(14.78)\end{array}$ & $\begin{array}{l}\text { G96 E1.5M2.5 } \\
(14.77)\end{array}$ & $\begin{array}{l}\text { G96.5 E0M3.5 } \\
(14.78)\end{array}$ \\
\hline 3 & $\begin{array}{l}\text { G90E10M0 } \\
(14.43)\end{array}$ & $\begin{array}{l}\text { G91.5E5M3.5 } \\
(14.43)\end{array}$ & $\begin{array}{l}\text { G92E3M5 } \\
(14.42)\end{array}$ & - \\
\hline 4 & $\begin{array}{l}\text { G85E15 M0 } \\
(14.09)\end{array}$ & $\begin{array}{l}\text { G86.8E9.5M3.7 } \\
(14.10)\end{array}$ & $\begin{array}{l}\text { G87.5E4M7.5 } \\
(14.11)\end{array}$ & - \\
\hline
\end{tabular}

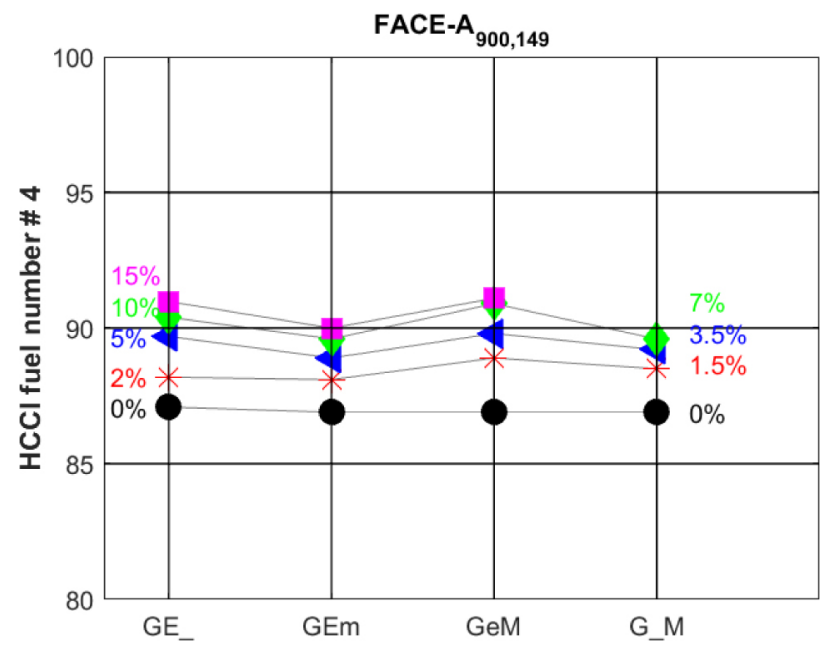

Figure 13. HCCI fuel number $\# 4$ at $900 \mathrm{rpm}, 149^{\circ} \mathrm{C}$ for FACE A, $\lambda=3$
Table 8. Combination (Cmb.) of GEM blends for FACE I (G represents FACE $\mathrm{I}$ and numbers adjoining letters indicate volume percentage)

\begin{tabular}{|c|l|l|l|l|}
\hline $\begin{array}{c}\text { Cmb. } \\
(\mathrm{A} / \mathrm{F}) \mathrm{s}\end{array}$ & \multicolumn{1}{|c|}{ GE_ } & \multicolumn{1}{|c|}{ GEm } & GeM & G_M \\
\hline 1 & $\begin{array}{l}\text { G98E2M0 } \\
(14.99)\end{array}$ & $\begin{array}{l}\text { G98.1E1.4 M0.5 } \\
(14.98)\end{array}$ & $\begin{array}{l}\text { G98.5 E0.5M1 } \\
(15.00)\end{array}$ & $\begin{array}{l}\text { G98.5E0M1.5 } \\
(14.98)\end{array}$ \\
\hline 2 & $\begin{array}{l}\text { G95E5M0 } \\
(14.78)\end{array}$ & $\begin{array}{l}\text { G95.8E2.5M1.7 } \\
(14.78)\end{array}$ & $\begin{array}{l}\text { G96 E1.5M2.5 } \\
(14.77)\end{array}$ & $\begin{array}{l}\text { G96.5 E0M3.5 } \\
(14.78)\end{array}$ \\
\hline 3 & $\begin{array}{l}\text { G90E10M0 } \\
(14.43)\end{array}$ & $\begin{array}{l}\text { G91.5E5M3.5 } \\
(14.43)\end{array}$ & $\begin{array}{l}\text { G92E3M5 } \\
(14.42)\end{array}$ & $\begin{array}{l}\text { G93E0M7 } \\
(14.43)\end{array}$ \\
\hline 4 & $\begin{array}{l}\text { G85E15 M0 } \\
(14.09)\end{array}$ & $\begin{array}{l}\text { G86.8E9.5M3.7 } \\
(14.10)\end{array}$ & $\begin{array}{l}\text { G87.5E4M7.5 } \\
(14.11)\end{array}$ & \\
\hline
\end{tabular}

Table 9. Combination (Cmb.) of GEM blends for FACE J (G represents FACE $\mathrm{J}$ and numbers adjoining letters indicate volume percentage)

\begin{tabular}{|c|l|l|l|l|}
\hline $\begin{array}{c}\text { Cmb. } \\
(\mathrm{A} / \mathrm{F}) \mathrm{s}\end{array}$ & \multicolumn{1}{|c|}{ GE_ } & \multicolumn{1}{|c|}{ GEm } & GeM & G_M \\
\hline 1 & $\begin{array}{l}\text { G98E2M0 } \\
(14.99)\end{array}$ & $\begin{array}{l}\text { G98.1E1.4 M0.5 } \\
(14.98)\end{array}$ & $\begin{array}{l}\text { G98.5 E0.5M1 } \\
(15.00)\end{array}$ & $\begin{array}{l}\text { G98.5E0M1.5 } \\
(14.98)\end{array}$ \\
\hline 2 & $\begin{array}{l}\text { G95E5M0 } \\
(14.78)\end{array}$ & $\begin{array}{l}\text { G95.8E2.5M1.7 } \\
(14.78)\end{array}$ & $\begin{array}{l}\text { G96 E1.5M2.5 } \\
(14.77)\end{array}$ & $\begin{array}{l}\text { G96.5 E0M3.5 } \\
(14.78)\end{array}$ \\
\hline 3 & $\begin{array}{l}\text { G90E10M0 } \\
(14.43)\end{array}$ & $\begin{array}{l}\text { G91.5E5M3.5 } \\
(14.43)\end{array}$ & $\begin{array}{l}\text { G92E3M5 } \\
(14.42)\end{array}$ & $\begin{array}{l}\text { G93E0M7 } \\
(14.43)\end{array}$ \\
\hline 4 & $\begin{array}{l}\text { G85E15 M0 } \\
(14.09)\end{array}$ & $\begin{array}{l}\text { G86.8E9.5M3.7 } \\
(14.10)\end{array}$ & $\begin{array}{l}\text { G87.5E4M7.5 } \\
(14.11)\end{array}$ & \\
\hline
\end{tabular}

Figure 14 displays the HCCI fuel number \# 1 for an engine speed of $600 \mathrm{rpm}$ and air inlet temperature of $52^{\circ} \mathrm{C}$ for PRF 70. It can be observed that the HCCI fuel number remains nearly constant for the low GEM combinations. A slope is observed at high concentrations showing that the iso-stoichiometric blending rule is less valid.

Figure 15 shows the effect of increasing the inlet air temperature for PRF 70 as base fuel. Similar behavior is when observed compared to low inlet air temperature (Fig. 14) except that for $15 \%$ concentration, an improvement in HCCI fuel number was observed.

Figure 16 illustrates the variation of HCCI fuel number \# 1 for four combinations of GEM blend for FACE I. A slope was observed showing a decrease in HCCI fuel number \#1 as ethanol is replaced by methanol among the GEM blends. The higher values for HCCI fuel number \#1 for $10 \%$ and $15 \%$ GEM combination indicates that ethanol had a greater octane enhancement effect when blended with gasoline. An increasing trend for HCCI fuel number \#1 was observed going from GeM to G_M, indicating that methanol, when blended alone with gasoline, gives high HCCI fuel numbers compared to the presence of ethanol in the mixture of gasoline-methanol.

Figure 17 shows the effect of increasing the inlet air temperature only. HCCI fuel number \#2 behaved much like HCCI \# 1(Fig. 16) except that a strong saturation effect was observed at GeM.

FACE J has a RON of 73.8, close to FACE I, which has a RON of 70.2 but has $30.5 \%$ more aromatic content. Figure 18 shows the HCCI fuel number \# 1 for an engine speed of $600 \mathrm{rpm}$ and air inlet 
temperature of $52^{\circ} \mathrm{C}$ for FACE J. It was observed that the HCCI fuel number remains nearly constant for all GEM combinations. A similar observation was found for HCCI fuel number \# 2 (Fig. 19).

Figure 20 shows the effect of speed only for PRF 70. A saturation behavior is observed for low concentrations at $\mathrm{P} 70 \mathrm{eM}$. A positive slope followed by a negative was observed at $10 \%$ concentrations.

Figure 21 is the combined effect of speed and inlet air temperature for PRF 70. Similar behavior was observed when compared to HCCI \#1 (Fig. 14), with an improvement in the HCCI fuel number at $15 \%$ concentration.

Figure 22 shows the effect of increasing the speed only with FACE I. Again, a similar behavior was observed with HCCI fuel number \# 1(ig. 16), with an improvement in the HCCI fuel numbers for all concentrations. The presence of slope in the GEM combinations shows that FACE I did not support the iso-stoichiometric blending rule.

Figure 23 displays the combined effect of speed and inlet air temperature for four GEM combinations with FACE I. It was found that as both speed and inlet air temperature increased, both ethanol and methanol had a saturation effect in all four cases of GE_, GEm, GmE and G_M. A local minima was observed at GeM for all four HCCI fuel numbers. The local minima were more dominant at higher engine speed of $900 \mathrm{rpm}$ and inlet air temperature of $149^{\circ} \mathrm{C}$. Once again, the presence of slopes for the GEM combinations point out that the iso-stoichiometric blending rule is not valid for FACE I.

A weaker slope at $15 \%$ concentration is observed for HCCI fuel number \# 3 and 4 (Fig. 24 and $\underline{25}$ ) for FACE J. For low concentrations, HCCI fuel number \# 3 and 4 behaved similarly to HCCI fuel number \# 1 (Fig. 18). FACE I and J with RON close to 70 behaved differently, possibly due to different aromatic concentrations.

Overall, PRF 70 and FACE I behaved similarly under some conditions, but differently under others. Both behaved similarly at low speed and low inlet air temperatures (Fig. 14 and 16). At higher inlet air temperatures, PRF 70 and FACE I behaved differently, with more saturation effect for FACE I (i․ 15 and 17). A similar local minima was observed for both FACE I and PRF 70 when only the speed is increased to $900 \mathrm{rpm}$ (Fig. 20 and 22). The combined effect of speed and inlet air temperature resulted in different behavior in both FACE I and PRF 70 (Fig. 21 and $\underline{23}$ ).

Overall, the 70 RON fuels do not show the same saturation effect in HCCI fuel number at high concentrations around 10 to $15 \%$ as were observed for the 84 RON fuels, with the exception of FACE I for HCCI fuel number \# 4 (Fig. 23). The absence of saturation effect for low RON fuels as compared to high RON fuels shows that base octane number has an important role in the behaviors of HCCI number but with the addition of ethanol/methanol, a high rate of increase for HCCI number is observed in the low RON fuel case. For 0 to $15 \%$ ethanol increase, the HCCI number changed approximately from 70 to 90 whereas for high RON fuels, the change was much less. It is well established that base fuels with lower RONs result in a greater increase in the RON with 10\% ethanol addition [22].

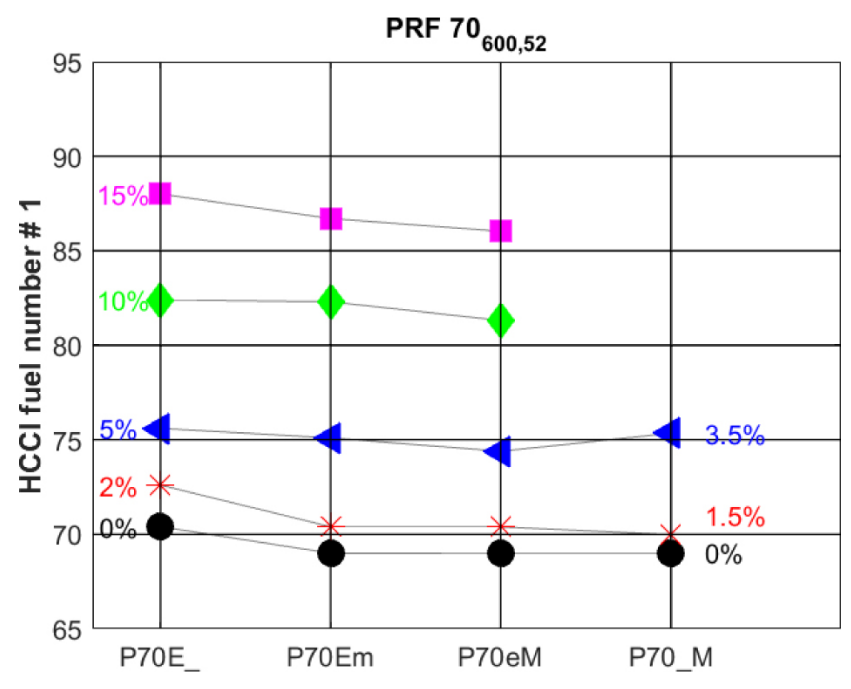

Figure 14. HCCI fuel number $\# 1$ at $600 \mathrm{rpm}, 52^{\circ} \mathrm{C}$ for PRF $70, \lambda=3$

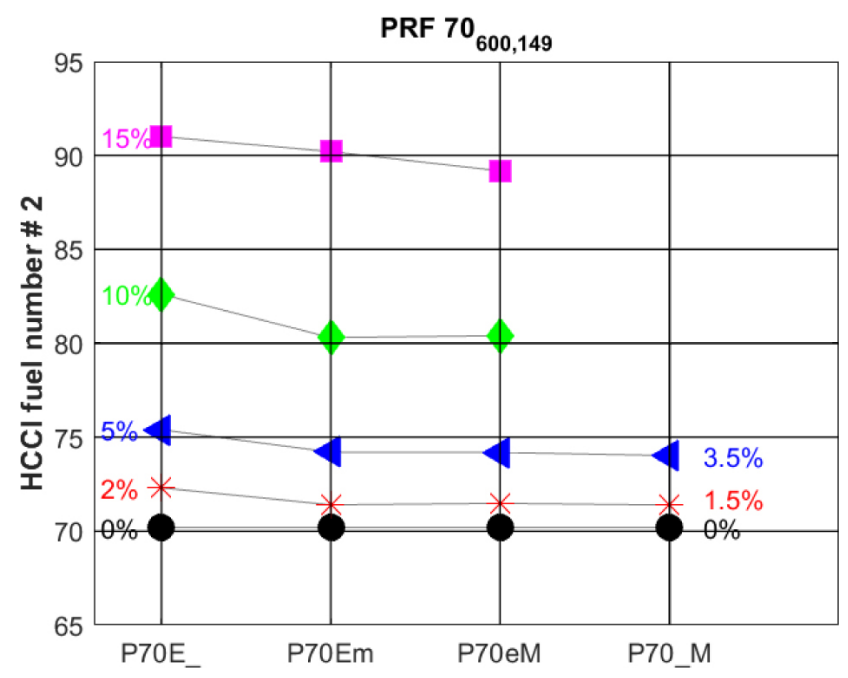

Figure 15. HCCI fuel number $\# 2$ at $600 \mathrm{rpm}, 149^{\circ} \mathrm{C}$ for PRF $70, \lambda=3$

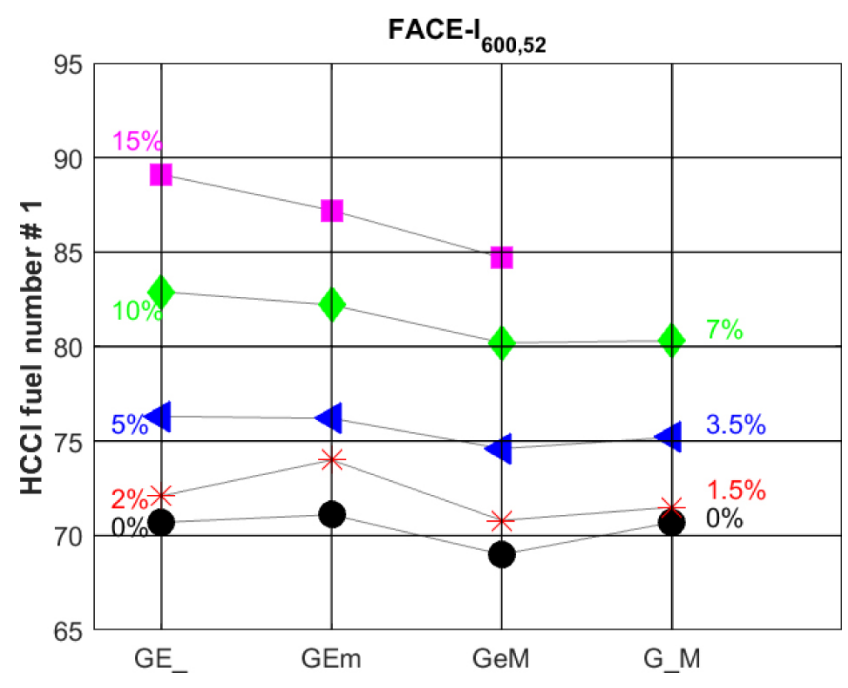

Figure 16. HCCI fuel number $\# 1$ at $600 \mathrm{rpm}, 52^{\circ} \mathrm{C}$ for FACE I, $\lambda=3$ 
FACE-I $_{600,149}$

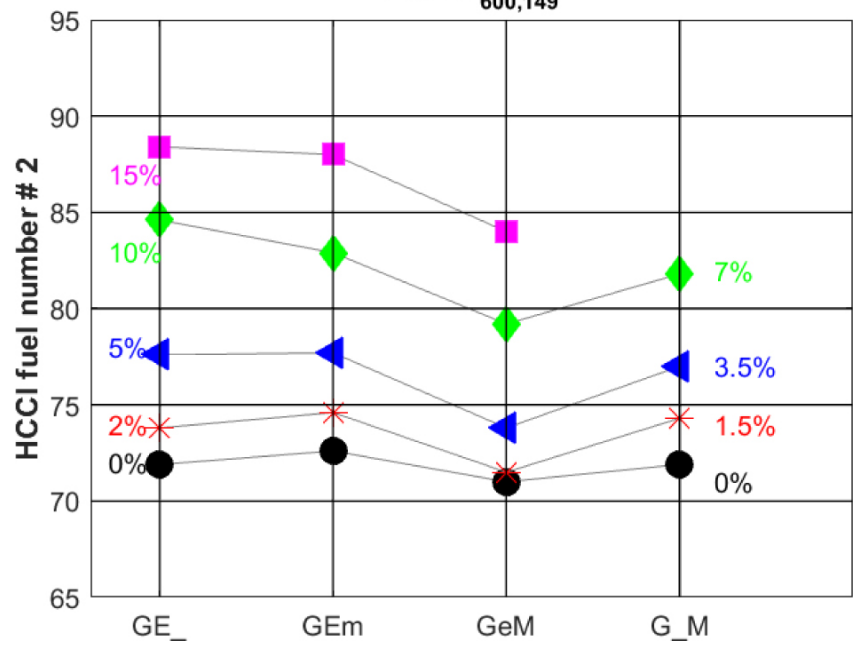

Figure 17. HCCI fuel number $\# 2$ at $600 \mathrm{rpm}, 149^{\circ} \mathrm{C}$ for FACE I, $\lambda=3$

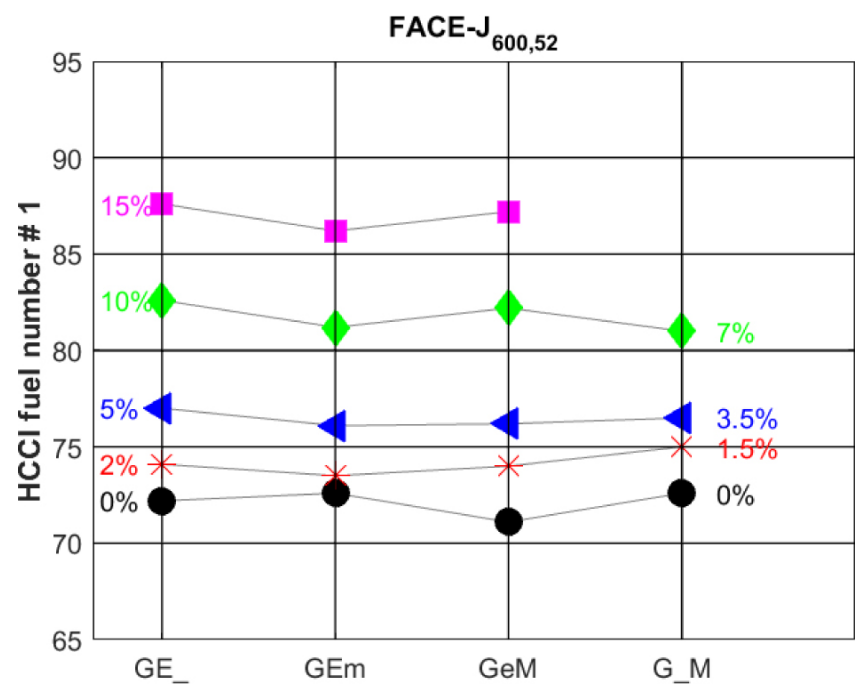

Figure 18. HCCI fuel number $\# 1$ at $600 \mathrm{rpm}, 52^{\circ} \mathrm{C}$ for FACE $\mathrm{J}, \lambda=3$

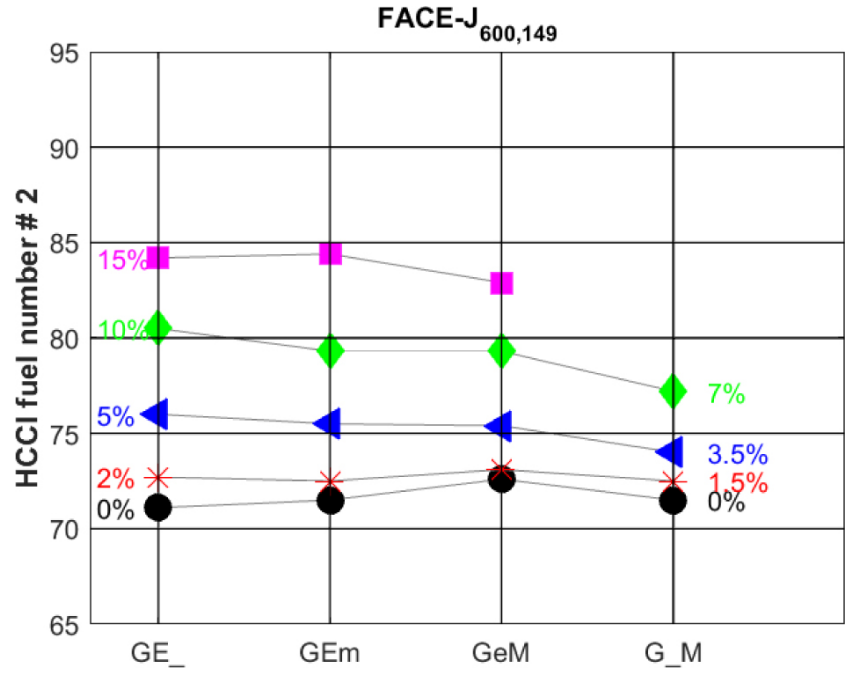

Figure 19. HCCI fuel number $\# 2$ at $600 \mathrm{rpm}, 149^{\circ} \mathrm{C}$ for FACE $\mathrm{J}, \lambda=3$

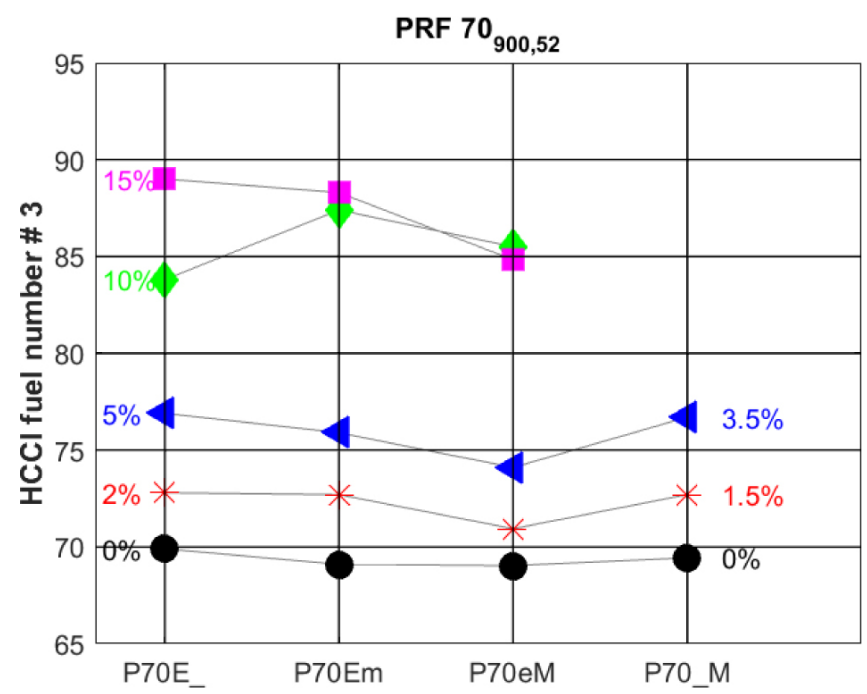

Figure 20. HCCI fuel number $\# 3$ at $900 \mathrm{rpm}, 52^{\circ} \mathrm{C}$ for PRF $70, \lambda=3$

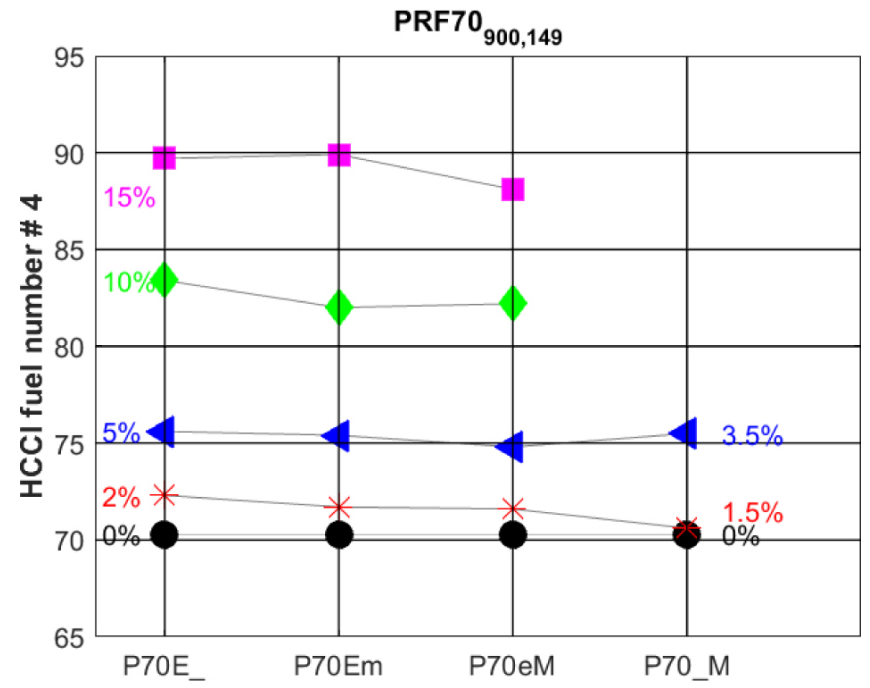

Figure 21. HCCI fuel number $\# 4$ at $900 \mathrm{rpm}, 149^{\circ} \mathrm{C}$ for PRF $70, \lambda=3$

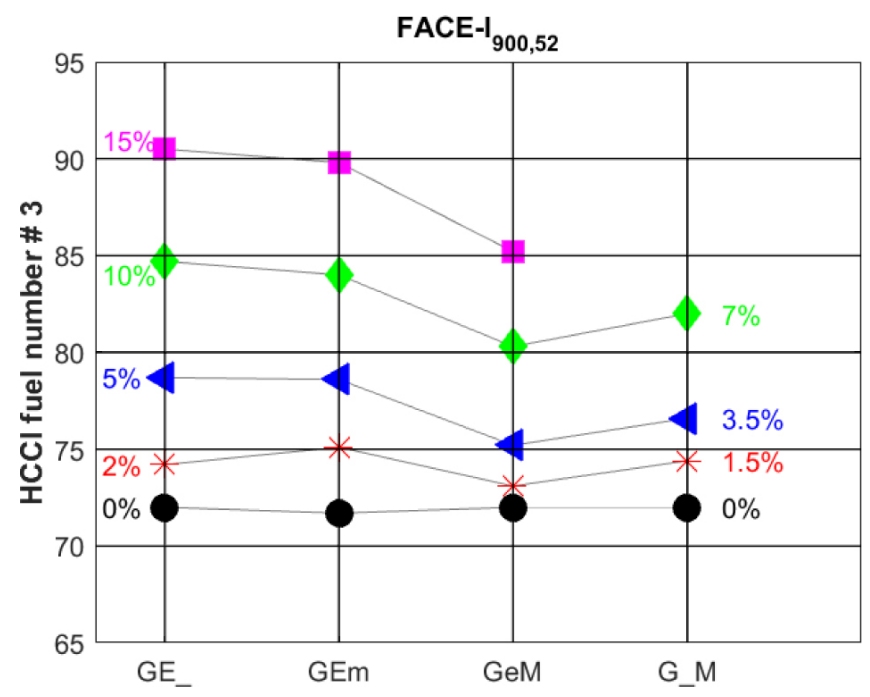

Figure 22. HCCI fuel number $\# 3$ at $900 \mathrm{rpm}, 52^{\circ} \mathrm{C}$ for FACE I, $\lambda=3$ 


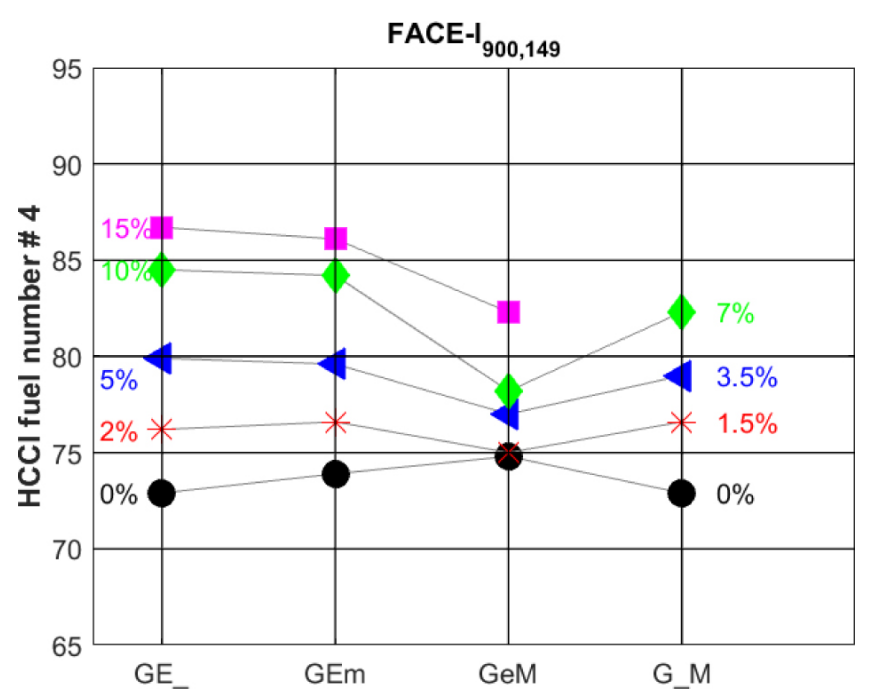

Figure 23. HCCI fuel number $\# 4$ at $900 \mathrm{rpm}, 149^{\circ} \mathrm{C}$ for FACE I, $\lambda=3$

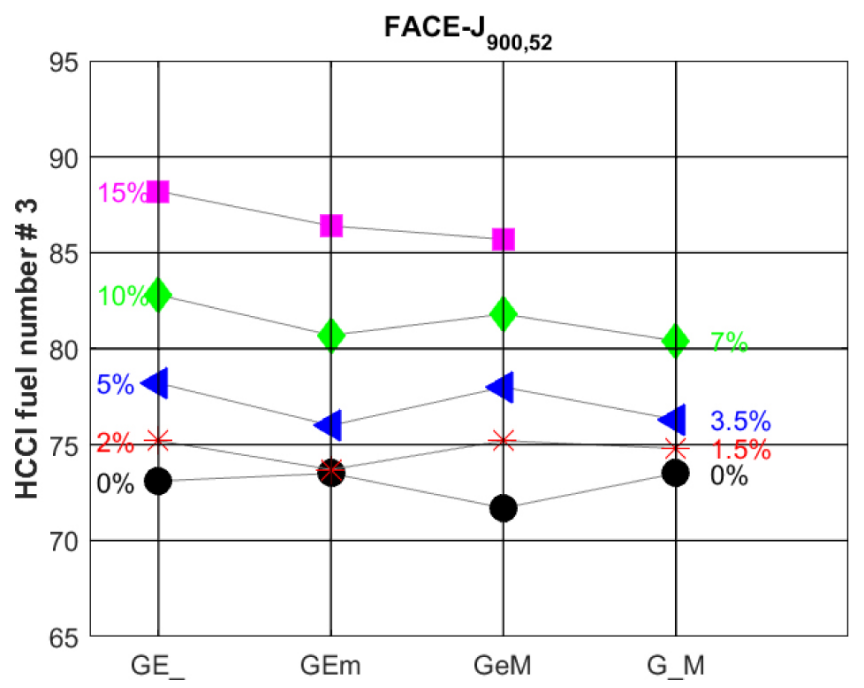

Figure 24. HCCI fuel number \# 3 at $900 \mathrm{rpm}, 52^{\circ} \mathrm{C}$ for FACE $\mathrm{J}, \lambda=3$

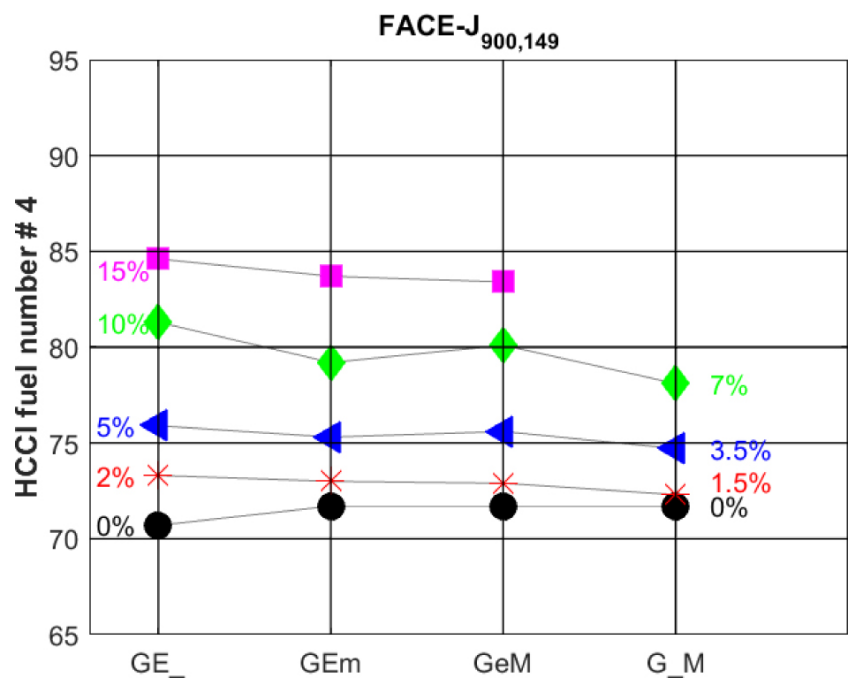

Figure 25. HCCI fuel number $\# 4$ at $900 \mathrm{rpm}, 149^{\circ} \mathrm{C}$ for FACE J, $\lambda=3$

\section{SI Results}

\section{High RON Fuels}

$\underline{\text { Figure } 26}$ and 27 show the variation of RON at an engine speed of $600 \mathrm{rpm}, 52^{\circ} \mathrm{C}$. The base fuels are PRF 84 and FACE A. It can be observed that in both base fuels, the RON remains about the same for any combination of GEM blends. This is consistent with the findings about high RON gasoline as a base fuel $[\underline{14}, \underline{26}]$ and the same as the HCCI fuel numbers.

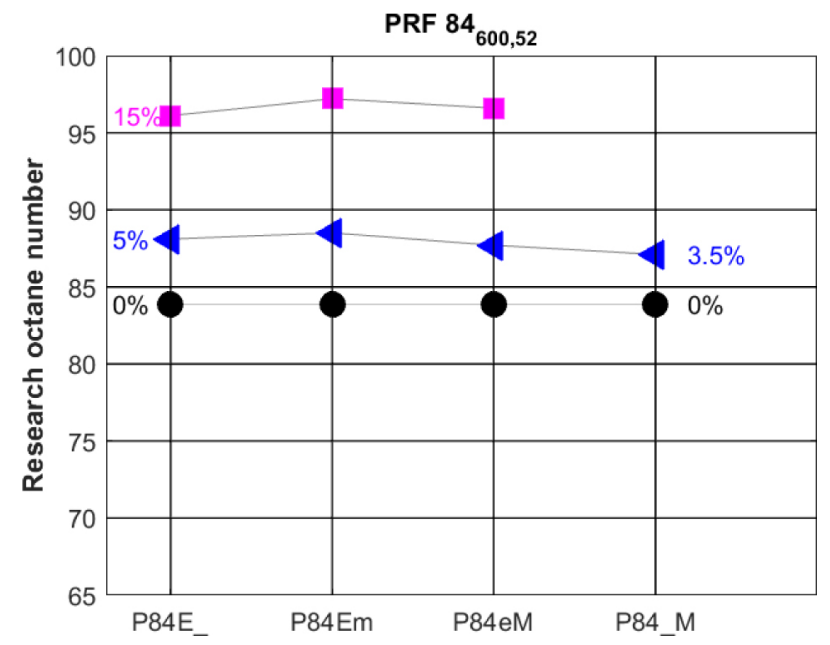

Figure 26. RON of PRF84 at $600 \mathrm{rpm}, 52^{\circ} \mathrm{C}$ in SI mode, spark timing $=13^{\circ}$ bTDC, $\lambda=1$

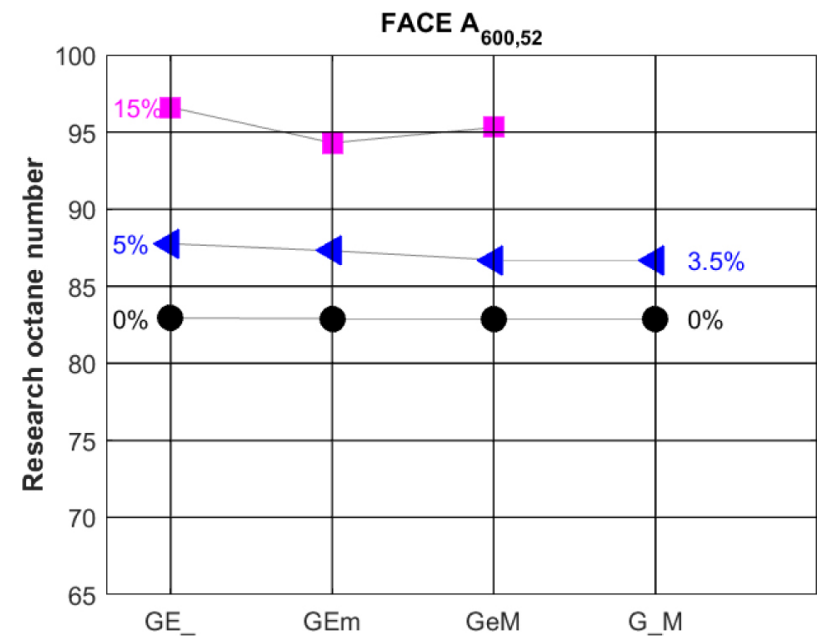

Figure 27. RON of FACE A at $600 \mathrm{rpm}, 52^{\circ} \mathrm{C}$ in SI mode spark timing $=13^{\circ}$ bTDC, $\lambda=1$

\section{Low RON Fuels}

Figure 28, 29 and $\underline{30}$ display the variation of RON at an engine speed of $600 \mathrm{rpm}, 52^{\circ} \mathrm{C}$. The base fuels used are PRF 70, FACE I and FACE J. A slope was observed at the high concentration (15\%), showing a decrease in RON as the methanol concentration increased across the combination of GEM blends. The presence of a negative slope was consistent with the findings of Turner et al. for low RON fuels [26]. The decrease could be attributed to the non-linear behavior of the addition of ethanol and methanol to the base fuels. In HCCI sections, FACE I and FACE J behaved differently, but in SI both seems to behave the same. 


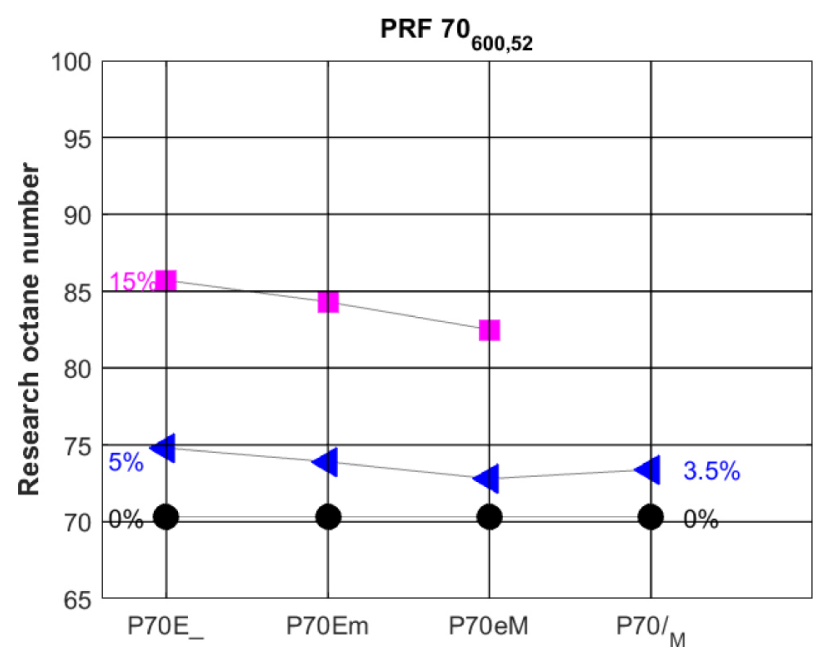

Figure 28. RON of PRF 70 at $600 \mathrm{rpm}, 52^{\circ} \mathrm{C}$ in SI mode, spark riming $=13^{\circ}$ bTDC, $\lambda=1$

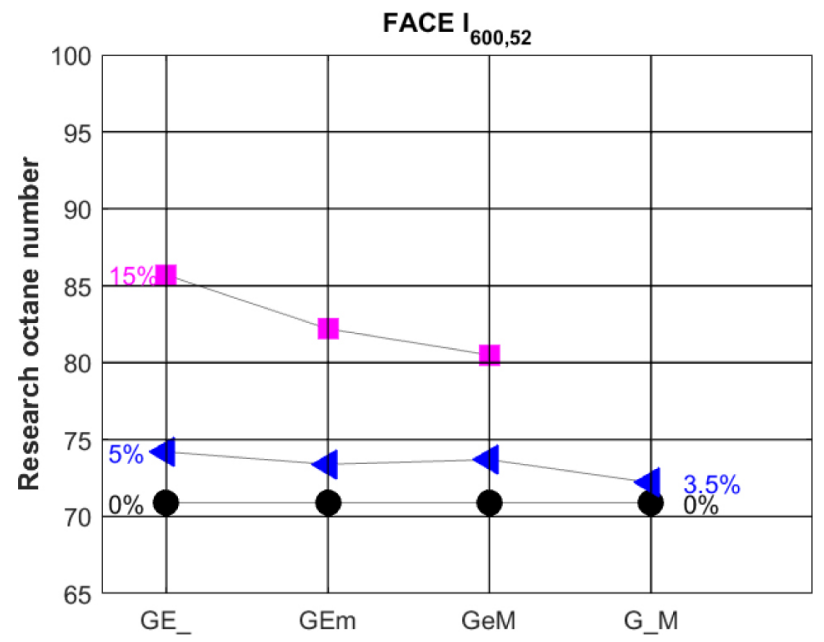

Figure 29. RON of FACE I at $600 \mathrm{rpm}, 52^{\circ} \mathrm{C}$ in SI mode, spark timing $=13^{\circ}$ bTDC, $\lambda=1$

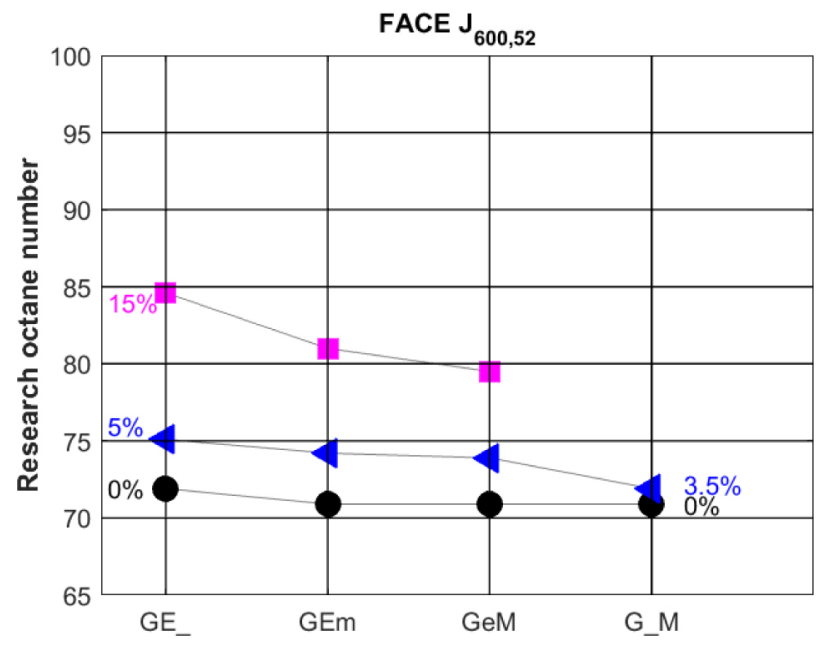

Figure 30. RON of FACE $\mathrm{J}$ at $600 \mathrm{rpm}, 52^{\circ} \mathrm{C}$ in SI mode, spark timing $=13^{\circ}$ bTDC, $\lambda=1$

\section{Results}

\section{High RON Fuels}

Figures 31 and 32 show the derived Research octane number for PRF 84 and FACE A. For comparison with HCCI and SI results, the derived cetane numbers were converted to derived research octane numbers and the plots for derived cetane number are included in the Appendix B. The derived research octane numbers for both the base fuels are about the same, showing that both behave similarly. A local minima was observed for FACE A and PRF 84 at GEm. Overall, all the base fuels appeared to behave similarly in CI combustion mode. The iso-stoichiometric blending rule seems to hold for high RON 84 fuel in SI and HCCI as well in CI.

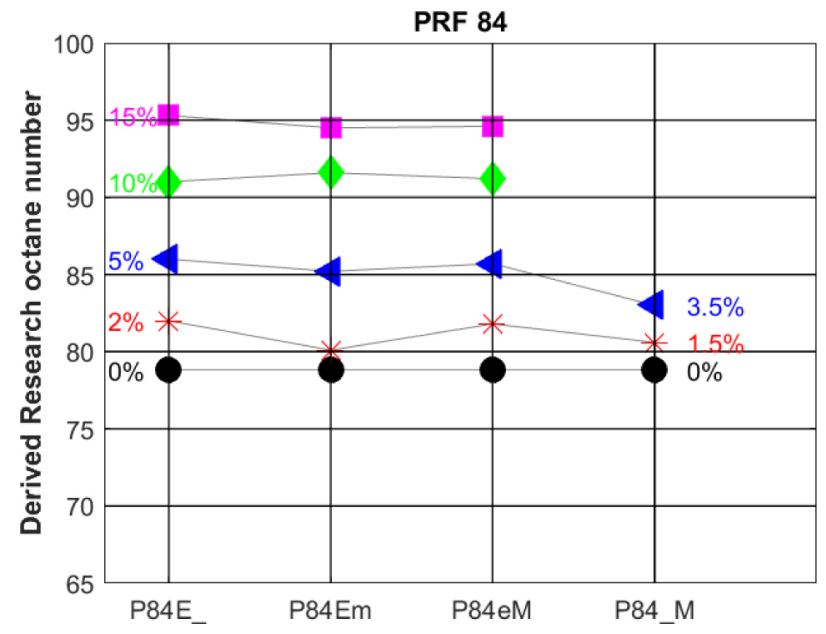

Figure 31. Derived Research octane number (DRON) for PRF 84

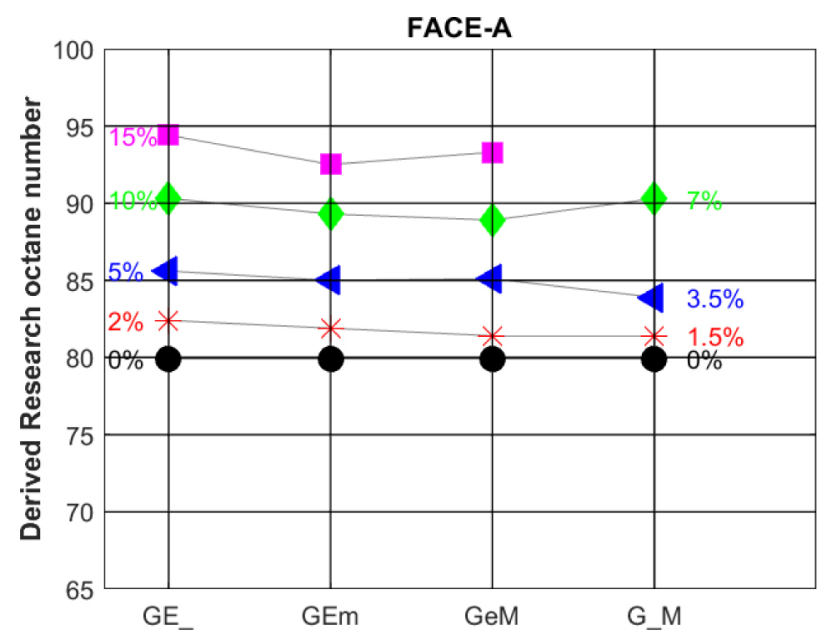

Figure 32. Derived Research octane number (DRON) for FACE A

\section{Low RON Fuels}

$\underline{\text { Figures } 33}, \underline{34}$ and $\underline{35}$ display the derived research octane number for PRF 70, FACE I and J. All the base fuels have RON close to 70. It was observed that the derived research octane number stayed about the same for all GEM combinations. A local minima was observed for all the 70 RON fuels at GEm and P70Em. A strong suppression of derived research octane number was observed for FACE $\mathrm{J}$ at GEm when compared to FACE I and PRF 70. This could be due to the high aromatic content (31.69\%) of FACE J. A local minima in HCCI was observed for FACE I at GeM. The presence of local minima for 
FACE I for both the CI and HCCI combustion modes indicate that it behaved similarly, but the position of local minima depends on the combustion mode operated.

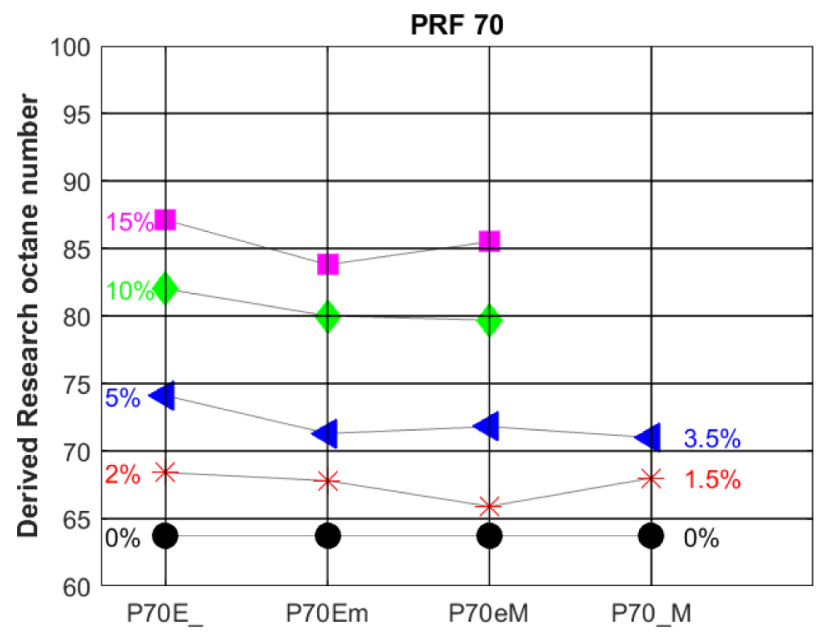

Figure 33. Derived Research octane number (DRON) for PRF 70

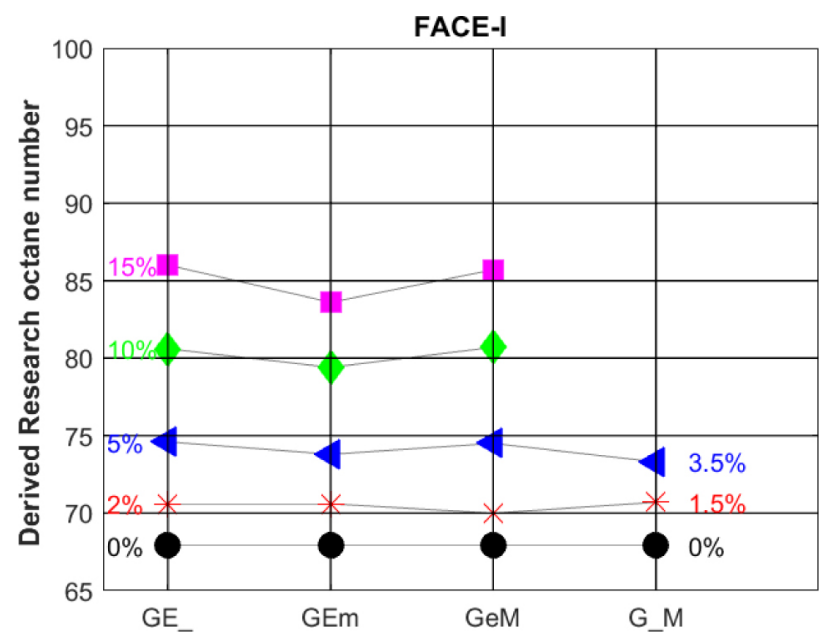

Figure 34. Derived Research octane number (DRON) for FACE I

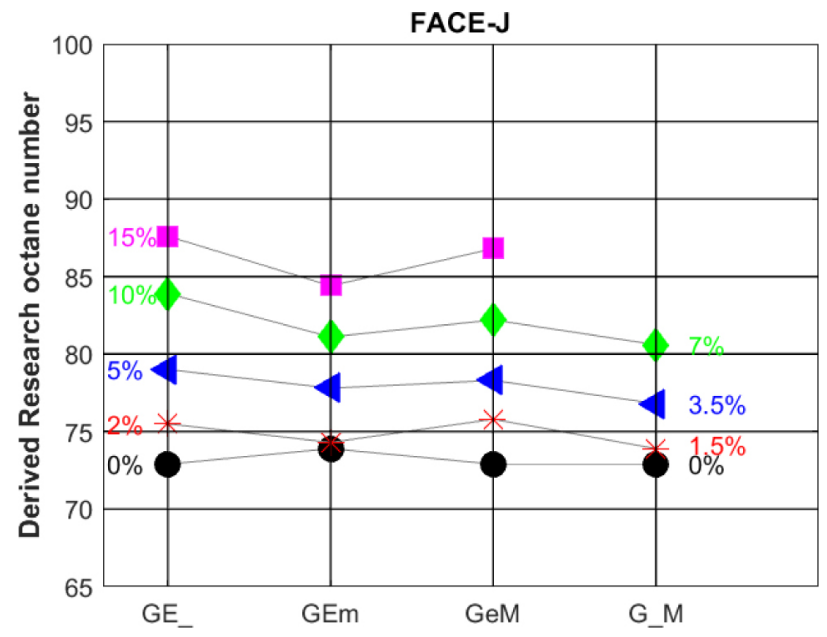

Figure 35. Derived Research octane number (DRON) for FACE J

\section{Iso-Stoichiometric Blending Rule}

The ternary GEM blends were derived from the binary combination of gasoline-ethanol (GE_). It was therefore decided to take GE_ as a benchmark and compare GEm, GeM and G_M by taking the ratio of octane numbers for GEm/GE_, GeM/GE_ and G_M/GE_. The ratio of $\mathrm{X} / \mathrm{GE} \_=1\left(\mathrm{X}=\mathrm{GEm}, \mathrm{GeM} \text { and } \mathrm{G}_{-} \mathrm{M}\right)$ was set as a criterion to determine whether the iso-stoichiometric blending rule was applicable to the five tested base fuels. Only two base fuels, FACE A (high RON) and FACE I (low RON) are selected to demonstrate the applicability of stoichiometric blending rule. The plots for other base fuels are included in Appendix D. Note that only HCCI fuel number \# 1 is selected for comparison with SI and CI mode. The figures for HCCI fuel number \# 2, 3 and 4 are also included in the Appendix D.

\section{High RON Fuel}

From Figures $36-\underline{38}$, it can be observed that high RON base fuels seem to be more applicable to the iso-stoichiometric blending rule. The data is less scattered around the horizontal line $(=1)$ for high RON fuels in all three combustion modes.

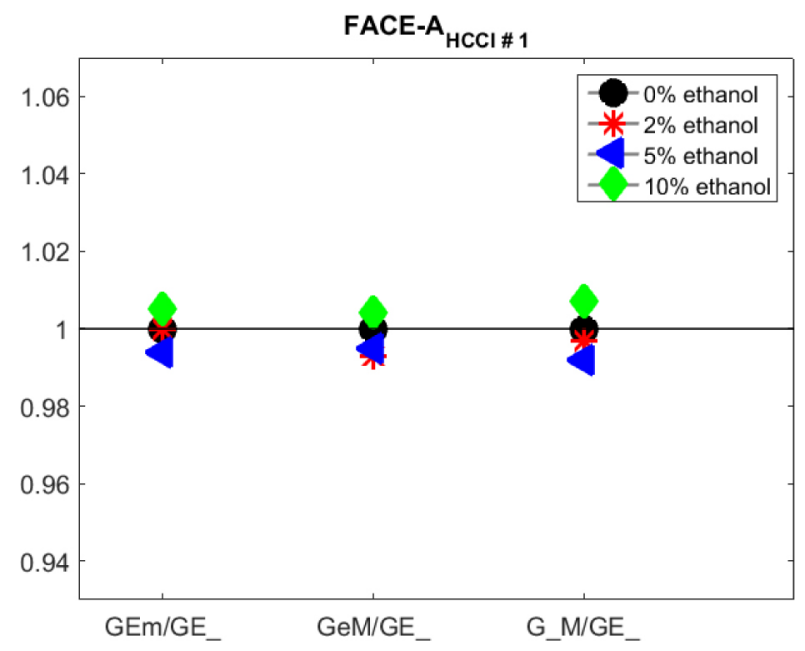

Figure 36. GEM verification for FACE A in HCCI mode

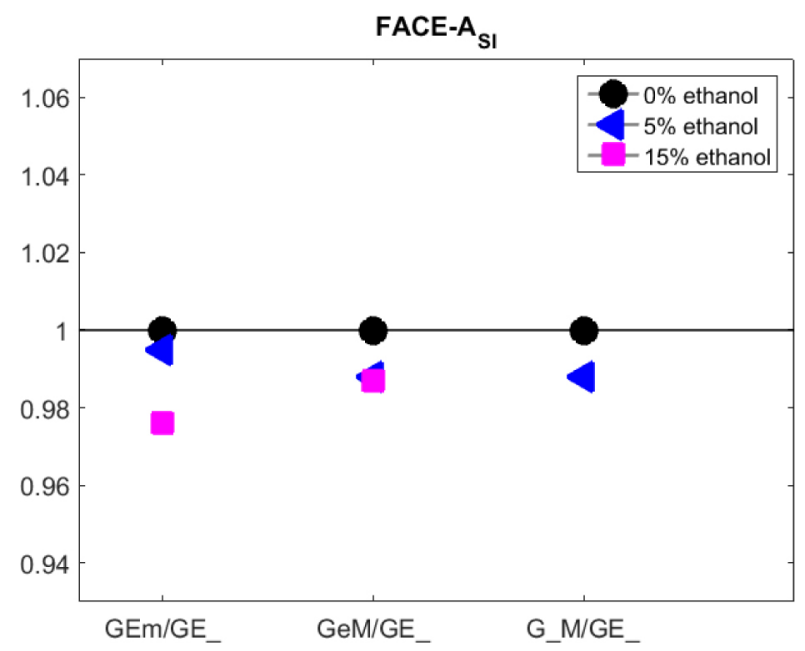

Figure 37. GEM verification for FACE A in SI mode 
FACE-A $_{\text {CI }}$

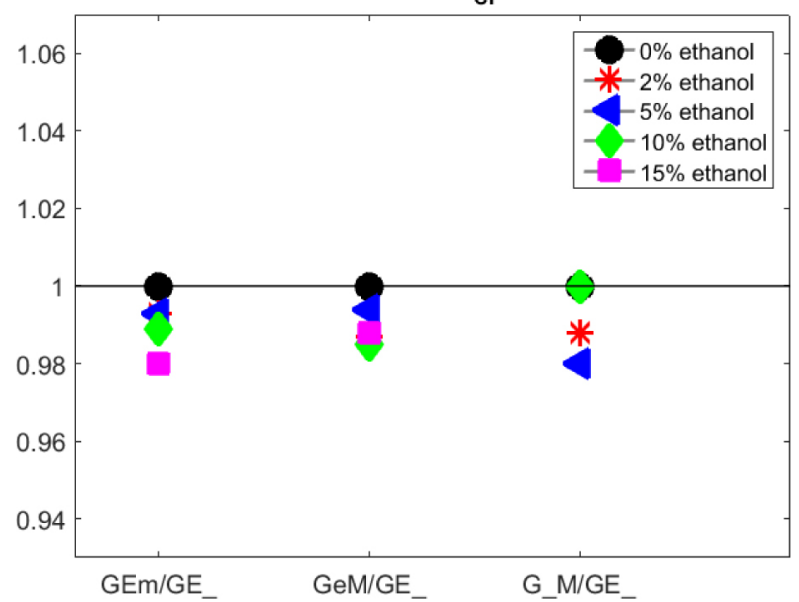

Figure 38. GEM verification for FACE A in CI mode

\section{Low RON Fuel}

From Figures 39-41, it could be observed that the presence of strong slopes led to a ratio of less than one for the low RON base fuels. The iso-stoichiometric blending rule therefore does not appear to agree well with the low RON base fuels.

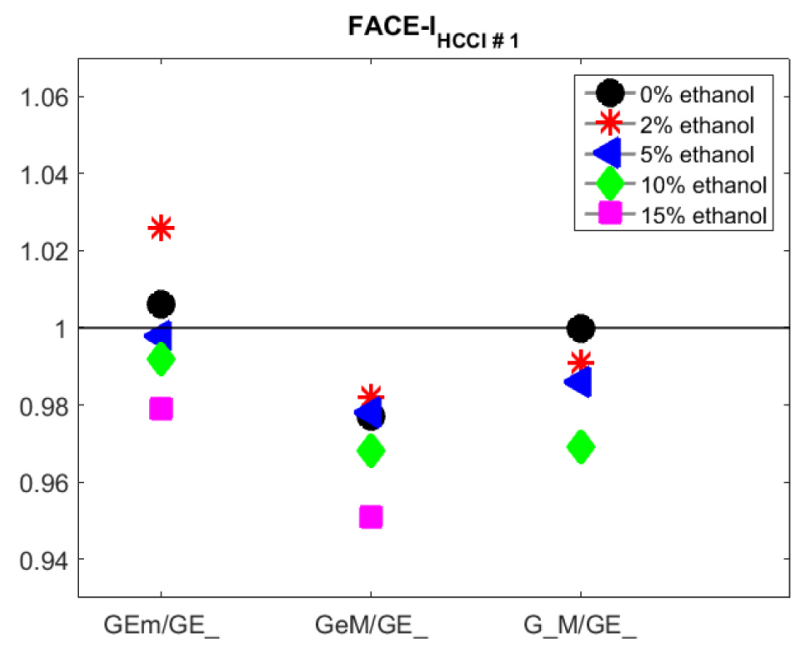

Figure 39. GEM verification for FACE I in HCCI mode

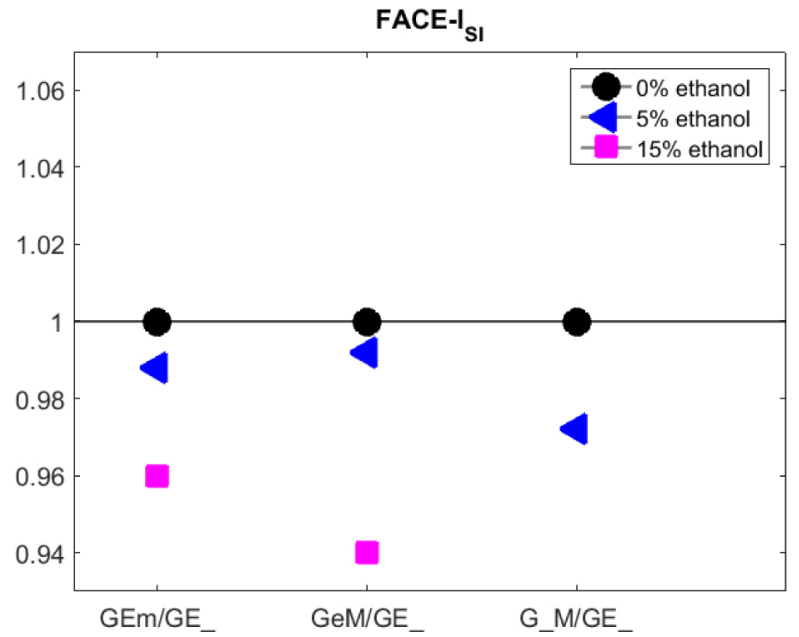

Figure 40. GEM verification for FACE I in SI mode
FACE-I

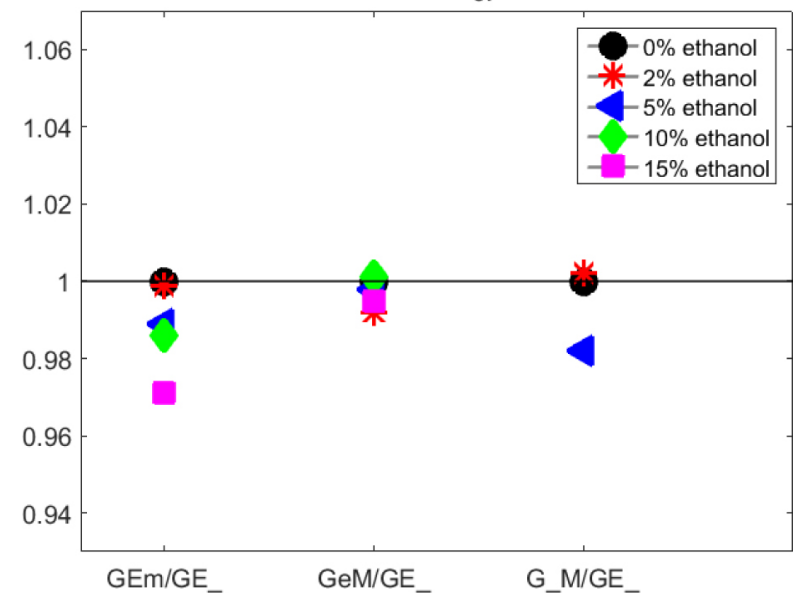

Figure 41. GEM verification for FACE I in CI mode

\section{Discussion}

One of the useful properties of ternary GEM blends derived from binary blends of gasoline-ethanol is that the RON, MON, heat of vaporization, and other properties, remains constant for all blends [14].To verify this using the iso-stoichiometric blending rule, GEM ternary blends, equivalent to binary combination of gasoline-ethanol blends (E2, E5, E10 and E15 in \% vol.) were experimentally tested in three combustion modes : HCCI, SI and CI.

It was found that for high RON base fuels, the difference in the octane number for the GEM blends was small as ethanol was replaced with methanol in all GEM combinations. This is consistent with the findings about on E85 and E15 GEM blends under SI conditions [르]. Other studies on E85 confirmed that the difference in octane numbers for E85 GEM blends was small [25, 28]. The base fuel octane number also had an important role in the behavior of GEM blends. For low RON fuels, it was found that the negative slope at higher concentrations of ethanol resulted in large differences in the octane numbers of GEM blends as ethanol was replaced with methanol. The same findings were observed by estimating the octane numbers using the molar blending rule for base gasoline with RON 75,85 and 95 [26]. The presence of negative slopes for the GEM blends of low aromatic fuels such as FACE I indicates that they behaved the same in both SI and HCCI combustion modes. GEM blends of FACE J with high aromatics (31.69\%) and RON 73.8 showed little difference in the octane numbers in the HCCI mode, but in SI the negative slope was observed. This indicates that GEM blends with a low RON base fuel can work well in the HCCI mode as long as the aromatic content is higher. For the HCCI operating range, fuel aromatic content and octane sensitivity are important characteristics of the fuel [49]. Fuel with greater than 35\% aromatic content, compared to high olefins, can increase the operating range for HCCI [ $\underline{49}$ ]. FACE J with $31.69 \%$ aromatics seems to be a suitable candidate for future HCCI engines.

However, other factors in using fuels with high aromatics needs to be considered, since the use of aromatics often leads to deposit formation within the combustion chamber. This would reduce the available volume that can lead to reduced compression ratios and therefore making the engine more prone to knock [ $\underline{50}]$. The porous nature of combustion chamber deposits can absorb the fuel supplied and release them in the following cycle causing an increase in the 
emissions. The development of CI engines is aimed at reducing soot and $\mathrm{NO}_{\mathrm{x}}$ without comprising efficiency [ $\underline{51}$ ]. A low RON gasoline with octane numbers in the range of 70 and 85 can address this problem [51]. In the future, FACE J with RON 73.8 and FACE A with RON 83.9 can be used for CI engines; both have shown nearly constant octane numbers with their GEM blends in CI mode.

The efficiency of SI engines, related to the anti-knock quality of the fuel, is a primary focus for the development of SI engines [51]. The addition of ethanol/methanol mixtures to the base fuels shows the increase in the RON or HCCI fuel number, displaying better anti-knock quality and the potential to introduce GEM blends to the market in the future.

Previous studies by this research group demonstrated that a small addition of ethanol to the base fuel can result in a non-linear response of RON [42]. This study demonstrates that the addition of methanol and combined mixtures of ethanol and methanol with base fuels also results in the non-linear response. Previous studies with a 10 to $15 \%$ methanol addition to the base gasoline also showed a non-linear response [19]. For the high RON fuels in this study, a saturation effect was found in the HCCI mode which proved that methanol is as effective as ethanol for octane enhancement. The presence of local minima for low RON fuels in the HCCI mode demonstrated that the combined mixtures of ethanol and methanol were not as effective as pure ethanol or methanol. This was also found to be true for the CI mode. In the SI mode, RON was found to be higher for gasoline-ethanol blends, showing that ethanol provided better octane enhancement.

\section{Conclusions}

In this research work, iso-stoicohometric blending rule was tested for low, medium and high concentrations of alcohols (ethanol and methanol) in FACE gasolines and PRFs. An experimental study was conducted in three different combustion modes: HCCI, SI and CI. Using the same stoichiometric air to fuel ratio per ethanol concentration into gasoline, ternary GEM blends were derived. The iso-stoichiometric blending rule states that for the same stoichiometric air-fuel ratio, a nearly constant octane enhancement effect across the GEM blends is observed. The following conclusions were reached:

- The iso-stoichiometric blending rule is valid for the small additions of ethanol or methanol, or mixtures of the two. This was found to be true for all base fuels.

- The iso-stoichiometric blending rule is not valid for higher concentrations of alcohols if low RON base fuels are used. This was found to be true for all the combustion modes operated.

- For high RON base fuels, the iso-stoichiometric blending rule was valid for high concentrations of alcohols independent of the combustion mode operated.

- The iso-stoichiometric blending rule was nearly applicable independent of the aromatic contents in the base fuels when operated in HCCI combustion mode. However, this was not applicable for SI and CI combustion mode.

- For the HCCI combustion mode and with high RON base fuels, the iso-stoichiometric blending rule was compliant at low and high speeds. This was not true for low RON base fuels.
- At low and high inlet air temperature for HCCI mode, the isostoichiometric blending rule agreed well. This was found to be true for high RON base fuels.

- The effect of ethanol and methanol to suppress auto-ignition was reduced for high RON base fuels in the HCCI mode resulting in a saturation behavior. Some saturation effect was also found for CI, but none was found for SI.

\section{References}

1. Splitter, D. and Szybist, J., "Intermediate Alcohol-Gasoline Blends, Fuels for Enabling Increased Engine Efficiency and Powertrain Possibilities," SAE Int. J. Fuels Lubr. 7(1):29-47, 2014, doi:10.4271/2014-01-1231.

2. Sarathy, SM., Oßwald, P., Hansen, N., and Kohse-Höinghaus, K., "Alcohol combustion chemistry," Progress in Energy and Combustion Science 44: 40-102, 2014, doi:10.1016/j. pecs.2014.04.003.

3. Sarathy, SM., "Fuel Class Higher Alcohols," (Wiley-VCH Verlag GmbH \& Co. KGaA,Weinheim, Germany, 2016), 29-57, doi:10.1002/9783527685318.ch2.

4. Iliev, S., "A comparison of ethanol and methanol blending with gasoline using a 1-D engine model," Procedia Engineering 100 : 1013-1022, 2015, doi:10.1016/j.proeng.2015.01.461.

5. Pearson, R., Turner, J., and Peck, A., "Gasoline-ethanolmethanol tri-fuel vehicle development and its role in expediting sustainable organic fuels for transport," presented at IMechE Low Carbon Vehicles Conference 2009, May 20-21, 2009.

6. Bechtold, R., Goodman, M., and Timbario, T., "Use of Methanol as a Transportation Fuel," Report prepared for Methanol Institute, Arlington, 2007.

7. Foong, T., Morganti, K., Brear, M., da Silva, G., "The octane numbers of ethanol blended with gasoline and its surrogates," Fuel, 115 :727-739, 2014, doi:10.1016/j.fuel.2013.07.105.

8. Partridge, R., Weissman, W., Ueda, T., Iwashita, Y., "Onboard Gasoline Separation for Improved Vehicle Efficiency," SAE Int. J. Fuels Lubr. 7(2):366-378, 2014, doi:10.4271/2014-01-1200.

9. Morganti, K., Abdullah, M., Alzubail, A., Viollet, Y. , "Improving the Efficiency of Conventional Spark-Ignition Engines Using Octane-on-Demand Combustion. Part I: Engine Studies," SAE Technical Paper 2016-01-0679, 2016, doi:10.4271/2016-01-0679.

10. Morganti, K., Alzubail, A., Abdullah, M., Viollet, Y. , "Improving the Efficiency of Conventional Spark-Ignition Engines Using Octane-on-Demand Combustion -Part II: Vehicle Studies and Life Cycle Assessment," SAE Technical Paper 2016-01-0683, 2016, doi:10.4271/2016-01-0683.

11. Chow, E., Heywood, J., and Speth, R., "Benefits of a Higher Octane Standard Gasoline for the U.S. Light-Duty Vehicle Fleet," SAE Technical Paper 2014-01-1961, 2014, doi:10.4271/2014-01-1961.

12. Lee, S., Speight, J., and Loyalka, S., "Handbook of alternative fuel technologies, Second Edition," Ch: 1(16) and 12 (397), eBook ISBN : 978-1-4665-9457-9, 2014. 
13. Bromberg, L., and Cheng, W., "Methanol as an alternative transportation fuel in the US: Options for sustainable and/ or energy-secure transportation," Final Report,Massachusetts Institute of Technology Cambridge, 2010.

14. Turner, J., Pearson, R., Purvis, R., Dekker, E. , "GEM Ternary Blends: Removing the Biomass Limit by using Iso-Stoichiometric Mixtures of Gasoline, Ethanol and Methanol," SAE Technical Paper 2011-24-0113, 2011, doi: 10.4271/2011-24-0113.

15. Sileghem, L., Coppens, A., Casier, B., Vancoillie, J., "Performance and emissions of iso-stoichiometric ternary GEM blends on a production SI engine," Fuel, 117 :286-293, 2014, doi:10.1016/j.fuel.2013.09.043.

16. Xie, H., Wei, Z., He, B., and Zhao, H., "Comparison of HCCI Combustion Respectively Fueled with Gasoline, Ethanol and Methanol through the Trapped Residual Gas Strategy," SAE Technical Paper 2006-01-0635, 2006, doi:10.4271/2006-01-0635.

17. Yahuza, I., and Dandakouta, H., "A Performance Review of Ethanol-Diesel Blended Fuel Samples in CompressionIgnition Engine," Journal of Chemical Engineering \& Process Technology 6(5) : 1-6, 2015, doi:10.4172/2157-7048.1000256.

18. Chupka, G., Christensen, E., Fouts, L., Alleman, T. , "Heat of Vaporization Measurements for Ethanol Blends Up to 50 Volume Percent in Several Hydrocarbon Blendstocks and Implications for Knock in SI Engines," SAE Int. J. Fuels Lubr. 8(2):251-263, 2015, doi:10.4271/2015-01-0763.

19. Anderson, J., Kramer, U., Mueller, S., and Wallington, T., "Octane numbers of ethanol- and methanol- gasoline blends estimated from molar concentrations," Energy \& Fuels 24(12):6576-6585, 2010, doi:10.1021/ef101125c.

20. Rankovic, N., Bourhis, G., Loos, M., and Dauphin, R., "Understanding octane number evolution for enabling alternative low RON refinery streams and octane boosters as transportation fuels," Fuel 150 : 41-47, 2015, doi:10.1016/j. fuel.2015.02.005.

21. Moran, D., "The Effects of Fuel Evaporation on the Octane Number of Methanol-Gasoline Blended Fuels," SAE Technical Paper 941861, 1994, doi: 10.4271/941861.

22. Anderson, J., Leone, T., Shelby, M., Wallington, T. , "Octane numbers of ethanol-gasoline blends: Measurements and novel estimation method from molar composition," SAE Technical Paper 2012-01-1274, 2012, doi:10.4271/2012-01-1274.

23. AlRamadan, A., Sarathy, SM., Khurshid, M., and Badra, J., "A blending rule for octane numbers of PRFs and TPRFs with ethanol," Fuel 180:175-186, 2016, doi:10.1016/j. fuel.2016.04.032.

24. Pearson, R., Turner, J., Bell, A., De Goede, S. , "Isostoichiometric fuel blends: characterisation of physicochemical properties for mixtures of gasoline, ethanol, methanol and water," Proceedings of the Institution of Mechanical Engineers, Part D: Journal of Automobile Engineering 229(1) : 111-139, 2015, doi:10.1177/0954407014529424.

25. Turner, J., Pearson, R., Dekker, E., Iosefa, B. , "Extending the role of alcohols as transport fuels using iso-stoichiometric ternary blends of gasoline, ethanol and methanol," Applied Energy 102 : 72-86, 2013,doi:10.1016/j.apenergy.2012.07.044.
26. Turner, J., Pearson, R., Bell, A., de Goede, S. , "IsoStoichiometric Ternary Blends of Gasoline, Ethanol and Methanol: Investigations into Exhaust Emissions, Blend Properties and Octane Numbers," SAE Int. J. Fuels Lubr. 5(3):945-967, 2012, doi:10.4271/2012-01-1586.

27. Tunér, M., "Combustion of Alternative Vehicle Fuels in Internal Combustion Engines," Report, Department of Energy Sciences, Lund University, 2015.

28. Turner, J., Pearson, R., McGregor, M., Ramsay, J. , "GEM ternary blends: testing iso-stoichiometric mixtures of gasoline, ethanol and methanol in a production flex-fuel vehicle fitted with a physical alcohol sensor," SAE Technical Paper 2012-01$\underline{1279}$, 2012, doi: $10.4271 / 2012-01-1279$.

29. Turner, J., Pearson, R., Dekker, E., Iosefa, B. , "Evolution of alcohol fuel blends towards a sustainable transport energy economy," In: MIT Energy Initiative Symposium : Prospects for Flexible- and Bi-Fuel Light Duty Vehicles 2012-04-19, 2012.

30. Truedsson, I., Cannella, W., Johansson, B., and Tuner, M., "Development of new test method for evaluating HCCI fuel performance," SAE Technical Paper 2014-01-2667, 2014, doi:10.4271/2014-01-2667.

31. ASTM D6890-16, "Standard Test Method for Determination of Ignition Delay and Derived Cetane Number (DCN) of Diesel Fuel Oils by Combustion in a Constant Volume Chamber," ASTM International, West Conshohocken, PA, 2016,doi:10.1520/D6890-16.

32. Bogin, G., Dean, A., Ratcliff, M., Luecke, J., "Expanding the Experimental Capabilities of the Ignition Quality Tester for Autoigniting Fuels," SAE Int. J. Fuels Lubr. 3(1):353-367, 2010, doi:10.4271/2010-01-0741.

33. Rosseel, E., and Sierens, R., "The physical and the chemical part of the ignition delay in diesel engines," SAE Technical Paper 961123, 1996, doi:10.4271/961123.

34. Yang, S., Naser, N., Chung, S., and Cha, J., "Effect of Temperature, Pressure and Equivalence Ratio on Ignition Delay in Ignition Quality Tester (IQT): Diesel, n-Heptane, and isoOctane Fuels under Low Temperature Conditions," SAE Int. J. Fuels Lubr. 8(3):537-548, 2015, doi:10.4271/2015-01-9074.

35. Naser, N., Yang, S., Kalghatgi, G., and Chung, S., "Relating the octane numbers of fuels to ignition delay times measured in an ignition quality tester (IQT)," Fuel 187: 117-127, 2017, doi:10.1016/j.fuel.2016.09.013.

36. Cannella, W., Foster, F., Gunter, G., and Leppard, W., "FACE Gasolines and Blends with Ethanol: Detailed Characterization of Physical and Chemical Properties," CRC Report No AVFL24, July, 2014.

37. Bhavani Shankar, V., Sajid, M., Al-Qurashi, K., Atef, N. , "Primary Reference Fuels (PRFs) as Surrogates for Low Sensitivity Gasoline Fuels," SAE Technical Paper 2016-010748, 2016, doi:10.4271/2016-01-0748.

38. Sarathy, SM., Kukkadapu, G., Mehl, M., Wang, W. , "Ignition of alkane-rich FACE gasoline fuels and their surrogate mixtures," Proceedings of the Combustion Institute 35(1):249-257, 2015, doi:10.1016/j.proci.2014.05.122. 
39. Ahmed, A., Goteng, G., Bhavani Shankar, V., Al-Qurashi, K. , "A computational methodology for formulating gasoline surrogate fuels with accurate physical and chemical kinetic properties," Fuel 143: 290-300, 2015, doi:10.1016/j. fuel.2014.11.022.

40. Chen, B., Togbé, C., Wang, Z., Dagaut, P. , "Jet-stirred reactor oxidation of alkane-rich FACE gasoline fuels.," Proceedings of the Combustion Institute, 2016, doi:10.1016/j. proci.2016.05.040.

41. Sarathy, S.M., Kukkadapu, G., Mehl, M., Javed, T. , "Compositional effects on the ignition of FACE gasolines," Combustion and Flame, 169, pp. 171-193, 2016.

42. Waqas, M., Naser, N., Sarathy, SM., Morganti, K., "Blending Octane Number of Ethanol in HCCI, SI and CI Combustion Modes," SAE Int. J. Fuels Lubr. 9(3):659-682, 2016, doi: 10.4271/2016-01-2298.

43. Kalghatgi, G., "Fuel anti-knock quality-Part I. Engine studies," SAE Technical Paper 2001-01-3584, 2001, doi:10.4271/2001-01-3584.

44. ASTM D2699-13b, "Standard Test Method for Research Octane Number of Spark-Ignition Engine Fuel," ASTM International, West Conshohocken, PA, 2013, doi:10.1520/D2699.

45. ASTM D2700-14, "Standard Test Method for Motor Octane Number of Spark-Ignition Engine Fuel," ASTM International, West Conshohocken, PA, 2016, doi:10.1520/D2700-16.

46. Chupka, G., Christensen, E., Fouts, L., Alleman, T. , "Heat of Vaporization Measurements for Ethanol Blends Up To 50 Volume Percent in Several Hydrocarbon Blendstocks and Implications for Knock in SI Engines," SAE Int. J. Fuels Lubr. 8(2):251-263, 2015, doi:10.4271/2015-01-0763.

47. Rankovic, N., Bourhis, G., Loos, M., and Dauphin, R., "Understanding octane number evolution for enabling alternative low RON refinery streams and octane boosters as transportation fuels," Fuel 150: 41-47, 2015, doi:10.1016/j. fuel.2015.02.005.

48. Foong, T., Morganti, K., Brear, M., da Silva, G. , "The effect of charge cooling on the RON of ethanol/gasoline blends," SAE Int. J. Fuels Lubr. 6(1):34-43, 2013, doi:10.4271/2013-01-0886.

49. Filipi, Z., Sathasivam, S., Cannella, W., and Fuentes-Afflick, P., "HCCI Operability Limits: The Impact of Refinery Stream Gasoline Property Variation," J. Eng. Gas Turbines Power 135(8), 081505, Jul 05, 2013, doi:10.1115/1.4024260.

50. Stępień, Z., "Intake valve and combustion chamber deposits formation-the engine and fuel related factors that impacts their growth," Nafta-Gaz70(4):236-242, 2014.
51. Kalghatgi, G., "The outlook for fuels for internal combustion engines," International Journal of Engine Research 15(4), 2014, doi: $10.1177 / 1468087414526189$.

\section{Contact}

Prof. Bengt Johansson

Bengt.Johansson@kaust.edu.sa

\author{
Definitions/Abbreviations \\ bTDC - Before top dead center \\ BON - Blending octane number \\ CAD - Crank angle degree \\ CA50 - Crank angle for 50\% heat release \\ CFR - Cooperative fuel research \\ CI - Compression ignition \\ DCN - Derived cetane number \\ DRON - Derived research octane number \\ FACE - Fuels for advanced combustion engines \\ HCCI - Homogeneous charge compression ignition \\ IQT - Ignition quality tester \\ PRFs - Primary reference fuels \\ MON - Motor octane number \\ RON - Research octane number \\ ST - Spark timing \\ SI - Spark ignition \\ TDC - Top dead center
}

\section{Acknowledgements}

The authors would like to thank the Clean Combustion Research Lab for providing the engine experiment facilities. The published paper was supported by competitive research funding from King Abdullah University of Science and Technology (KAUST) and funds from Saudi Aramco under the FUELCOM program. The author also wishes to thank Mohamd Almansour and Ahmad Radhwan at the Saudi Aramco Research \& Development Center for preparing and analyzing the test fuels. I would also like to thanks Kate McClintock for correcting the English Language. 


\section{$\underline{\text { APPENDIX }}$}

\section{APPENDIX A}

Table A1. Constant values for best fit line belonging to reference curve of SI condition [늘

\begin{tabular}{|l|l|l|l|}
\hline Operating Condition & $x$ & $y$ & $z$ \\
\hline $\begin{array}{l}\text { RON-(600rpm, } \mathrm{T}_{\mathrm{in}}= \\
\left.52^{\circ} \mathrm{C}\right)\end{array}$ & -8.2937 & 122.68 & -353.86 \\
\hline
\end{tabular}

Table A2. Constant values for best fit lines belonging to reference curves of four HCCI conditions [느]

\begin{tabular}{|l|l|l|l|}
\hline Operating conditions & \multicolumn{1}{|c|}{$d$} & \multicolumn{1}{c|}{$e$} & $f$ \\
\hline HCCI-1(RON) & -2.1832 & 62.031 & -349.16 \\
\hline HCCI-2 & -0.8739 & 26.224 & -102.04 \\
\hline HCCI-3 & -0.9988 & 33.876 & -191.74 \\
\hline HCCI-4(MON) & -0.2641 & 13.232 & -42.738 \\
\hline
\end{tabular}

\section{APPENDIX B}

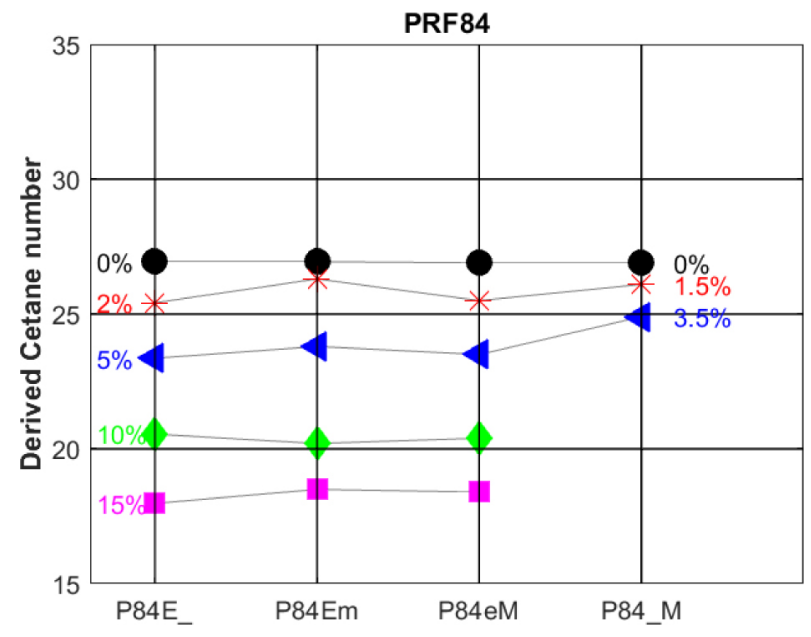

Figure A1. Derived Cetane number (DCN) for PRF 84
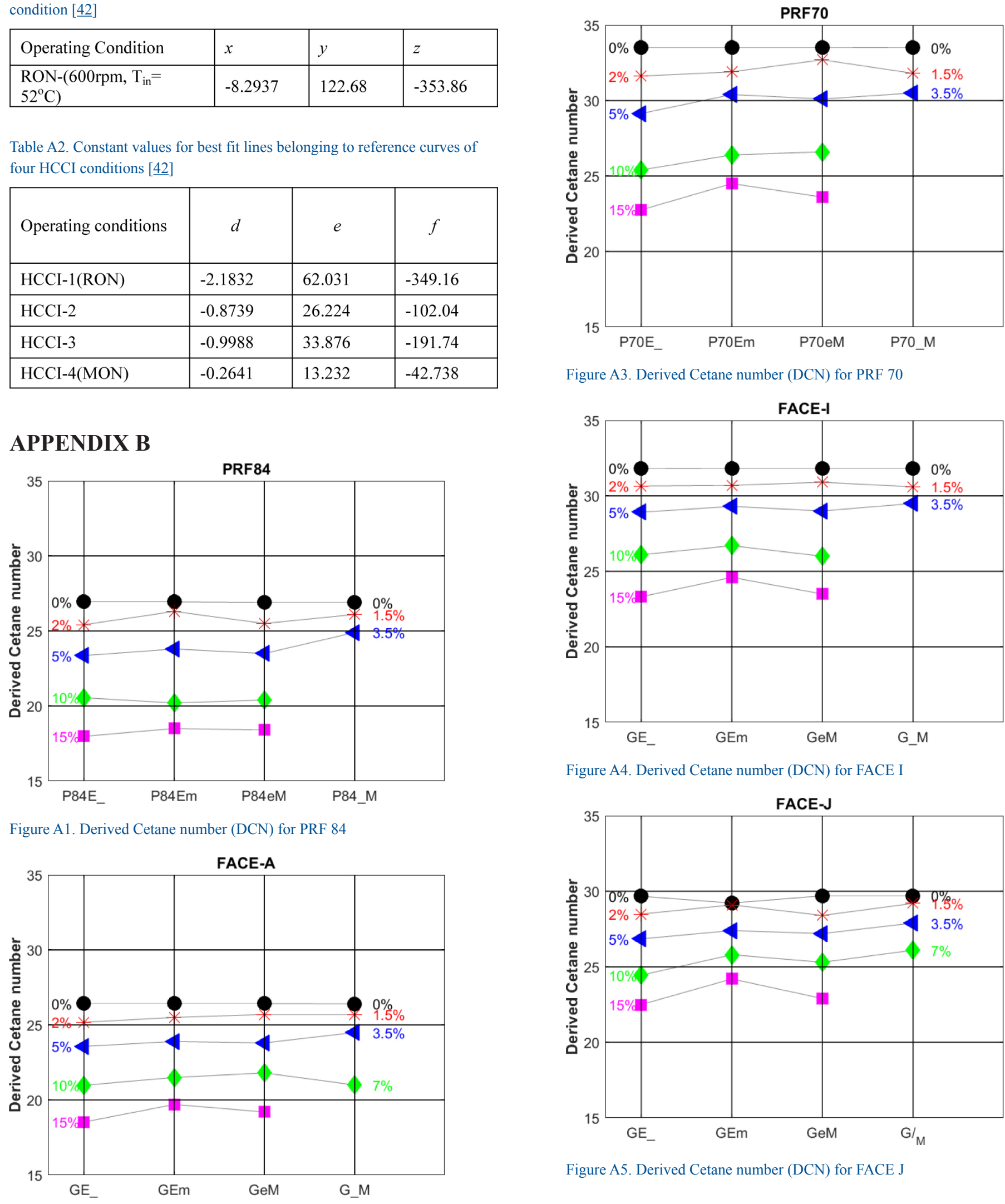

Figure A3. Derived Cetane number (DCN) for PRF 70

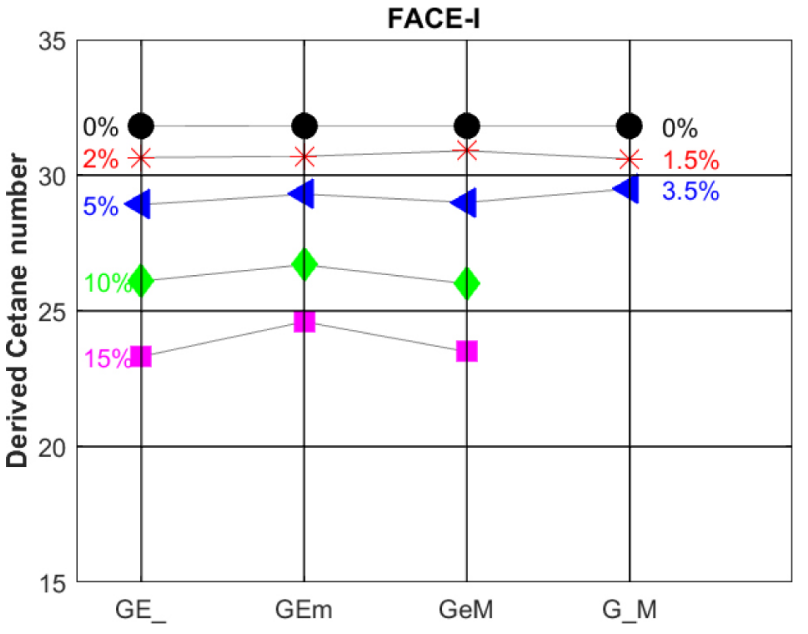

Figure A4. Derived Cetane number (DCN) for FACE I

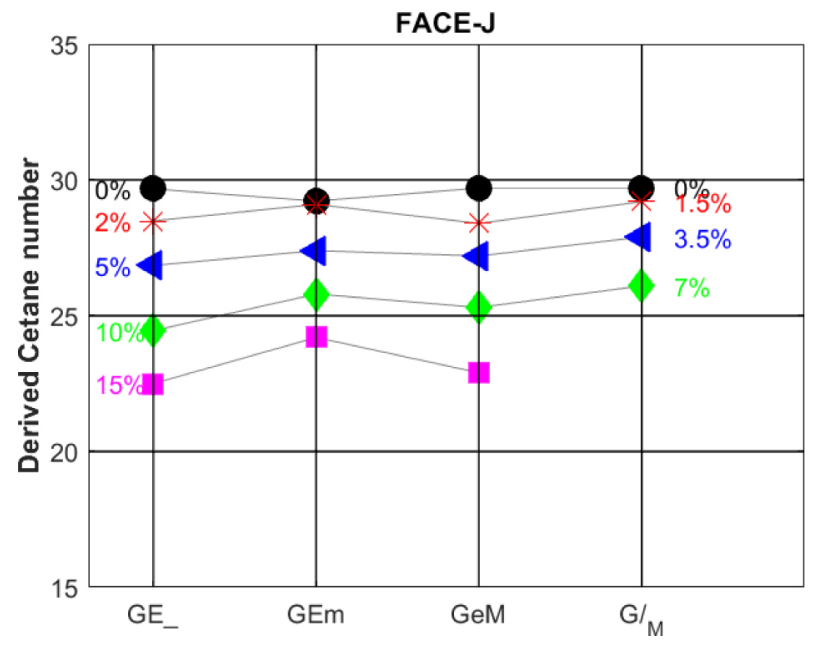

Figure A5. Derived Cetane number (DCN) for FACE J

Figure A2. Derived Cetane number (DCN) for FACE A 


\section{APPENDIX C}

\section{BLENDING OCTANE NUMBER}

The non-linear behavior of RON with the addition of ethanol and methanol has led to a definition of blending octane number. Both the ethanol and methanol have RON close to 108, and if the non-linearity did not exist, the blending octane number would have been constant and equal to the octane number of the pure component []].

The blending octane number can be defined in terms of base fuel RON (for the current study, FACE fuels and PRF solutions at $0 \%$ ethanol (GE_), $0 \%$ methanol (G_M), $0 \%$ ethanol + methanol $(\mathrm{GEm} / \mathrm{GeM})$ ), the concentration of the base fuel, the booster concentration (for the present study, ethanol, methanol and the sum of ethanol and methanol) and the blending RON (BRON) [므, 20].

For the case of SI mode, BON can be expressed as:

$$
R O N_{b a s e} \cdot X_{\text {base }}+\text { BON. } X_{\text {booster }}=\text { RON }_{\text {mix }}
$$

Where $R O N_{\text {base }}=$ RON of the base fuel

$X_{\text {base }}=$ concentration of the base fuel

$X_{\text {booster }}=$ concentration of the booster (For GE_(ethanol), G_M (methanol), GEm (ethanol+methanol), GeM (ethanol + methanol)

$R O N_{\text {mix }}=$ octane numbers of the GEM blends

For HCCI mode, equation 3 can be expressed as:-

$$
H_{C C I} \text { base } . X_{\text {base }}+B O N . X_{\text {booster }}=H C C I_{\text {mix }}
$$

Where $\mathrm{HCCI}_{\text {base }}=\mathrm{HCCI}$ fuel number for the base fuel

$X_{\text {base }}=$ concentration of the base fuel

$X_{\text {booster }}=$ concentration of the booster (For GE_(ethanol), G_M (methanol), GEm (ethanol+methanol), GeM (ethanol+methanol)

$H C C I_{m i x}=$ HCCI fuel numbers of the GEM blends

The blending octane number has been used previously to understand the non-linear behavior of base gasoline caused by the addition of ethanol and methanol $[\underline{19}, \underline{20}, \underline{42}]$. The results demonstrated that base fuel composition and base octane number play an important role in the evolution of RON with an ethanol addition. More details about the blending octane number appear in a previous publication by this author [느]

The blending octane number was used in this study to understand suppression of auto-ignition caused by the addition of ethanol/methanol mixtures with the base fuels. The blending octane number was positive and found to be around 250 for small concentrations of ethanol/methanol in SI and HCCI modes. The base fuel octane rating and composition played an important role in the behavior of blending octane numbers. The blending octane number for some base fuels decreased and for some the number increased with the addition of ethanol/methanol, while for some fuels it stayed reasonably constant. 


\section{APPENDIX D}

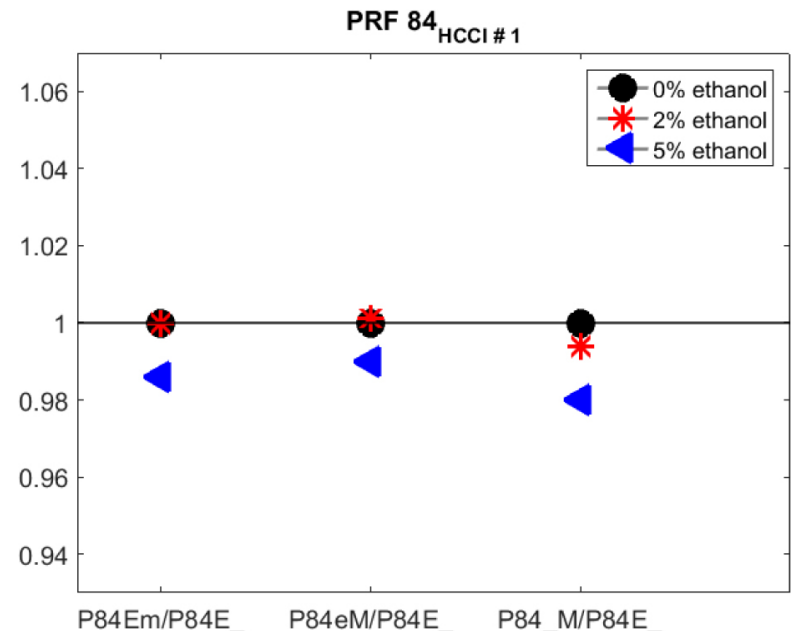

Figure A6. GEM verification for PRF 84 in HCCI mode

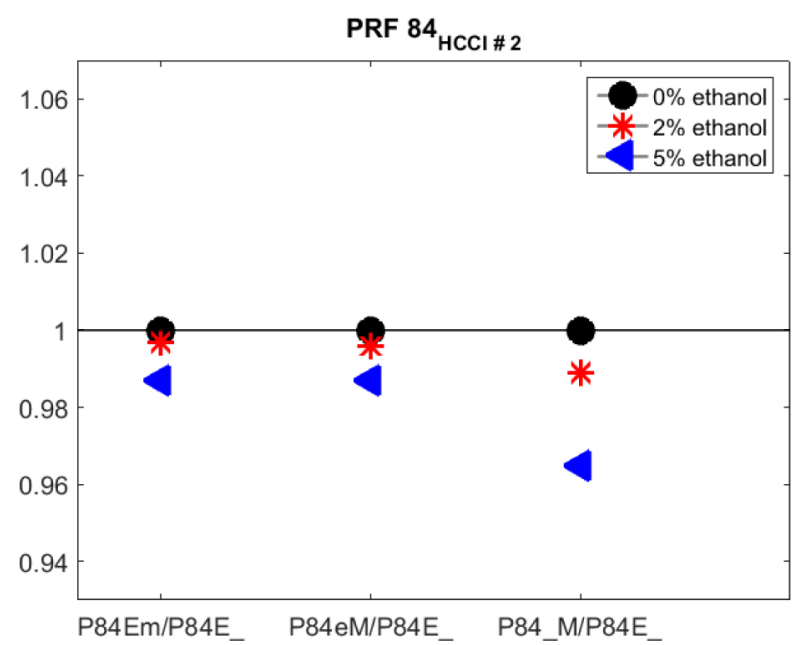

Figure A7. GEM verification for PRF 84 in HCCI mode

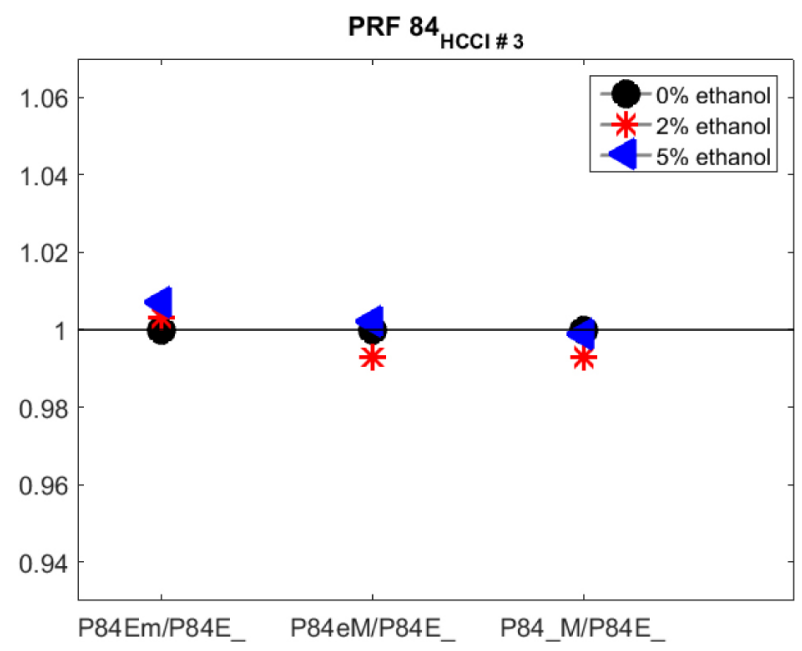

Figure A8. GEM verification for PRF 84 in HCCI mode
PRF $84_{\mathrm{HCCl}}$ 4

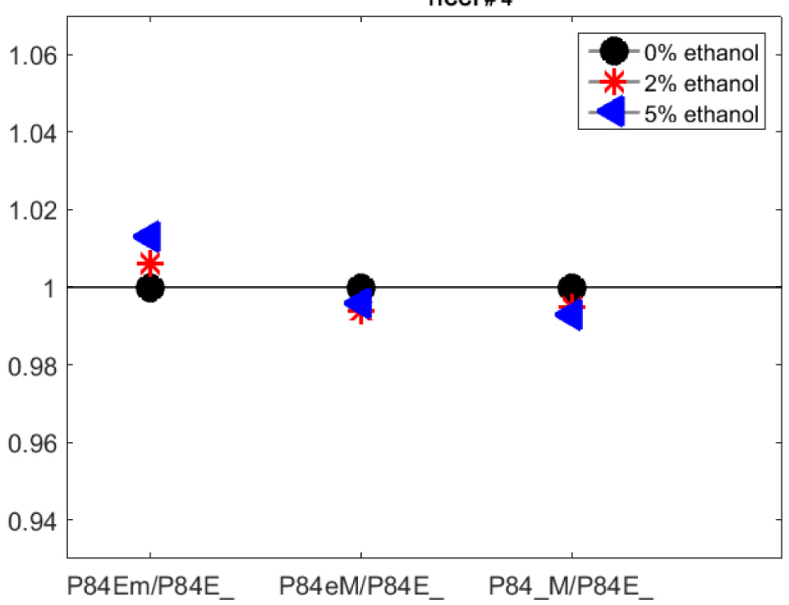

Figure A9. GEM verification for PRF 84 in HCCI mode

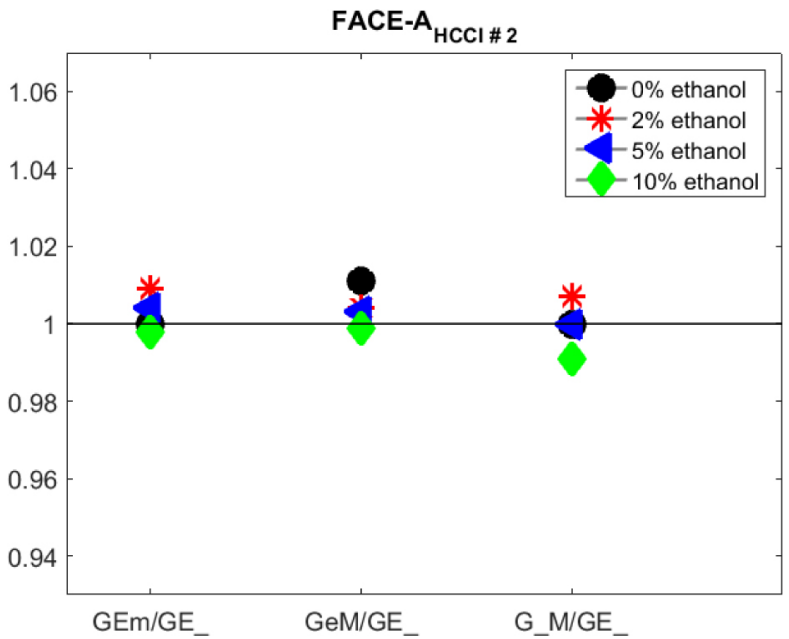

Figure A10. GEM verification for FACE A in HCCI mode

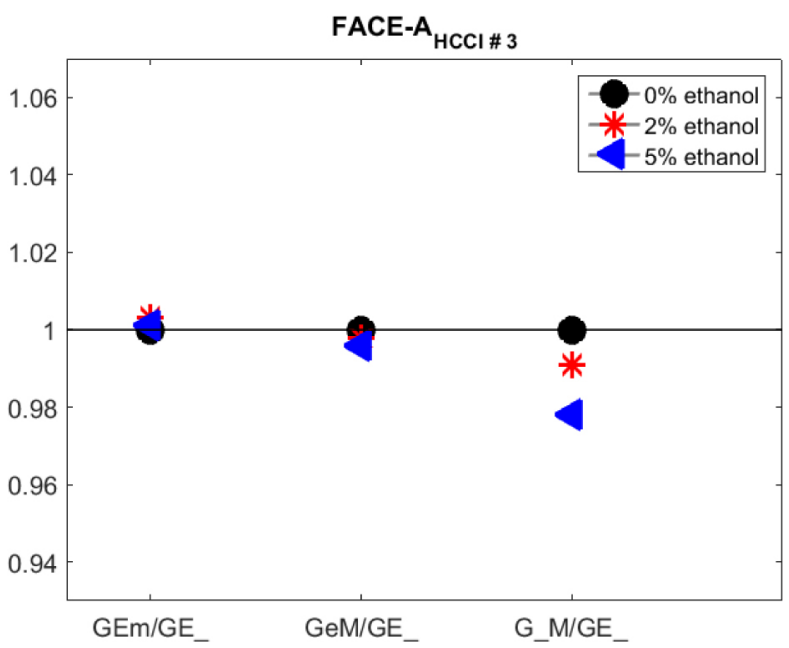

Figure A11. GEM verification for FACE A in HCCI mode 
FACE-A ${ }_{\mathrm{HCCl}} \# \mathbf{4}$

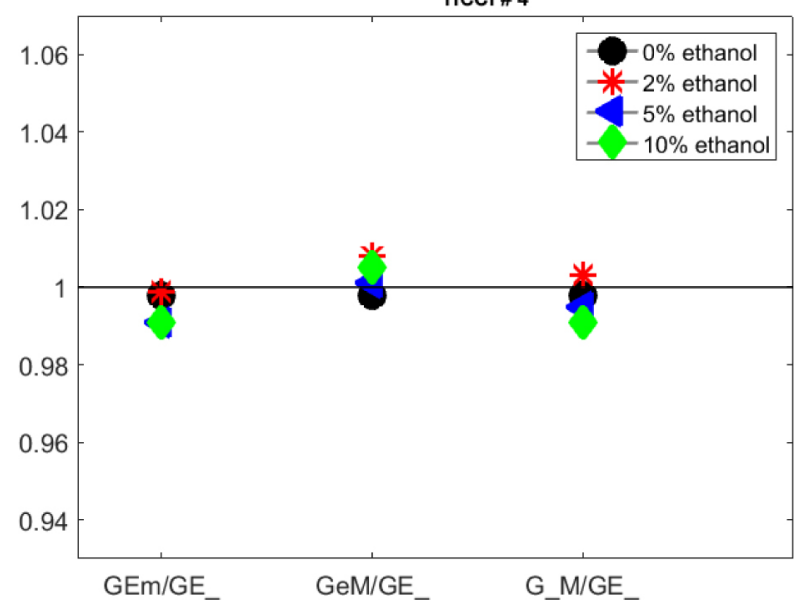

Figure A12. GEM verification for FACE A in HCCI mode

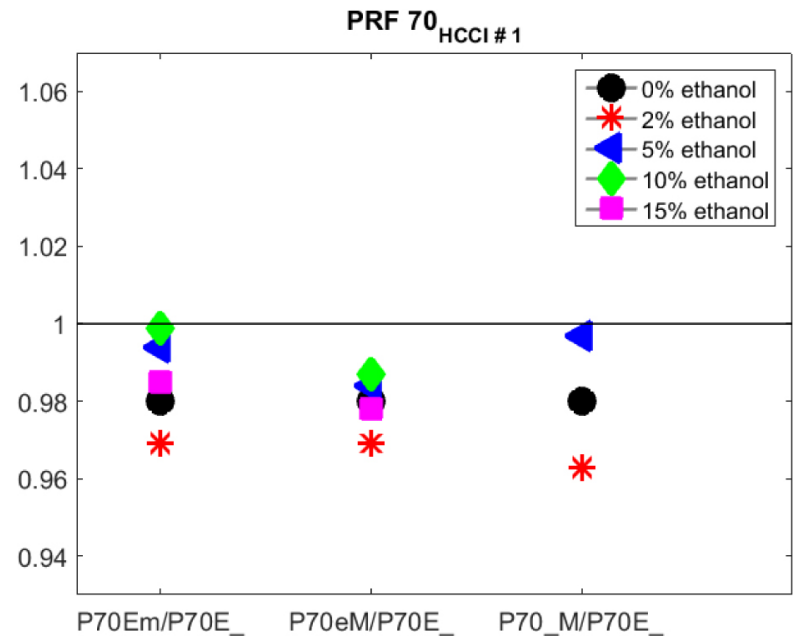

Figure A13. GEM verification for PRF 70 in HCCI mode

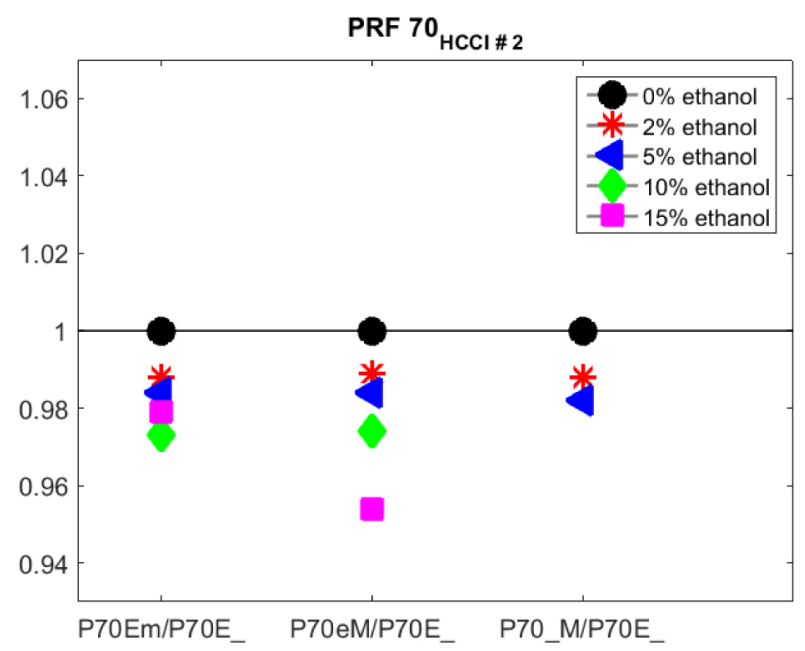

Figure A14. GEM verification for PRF 70 in HCCI mode
PRF $70_{\mathrm{HCCl}}$ 3

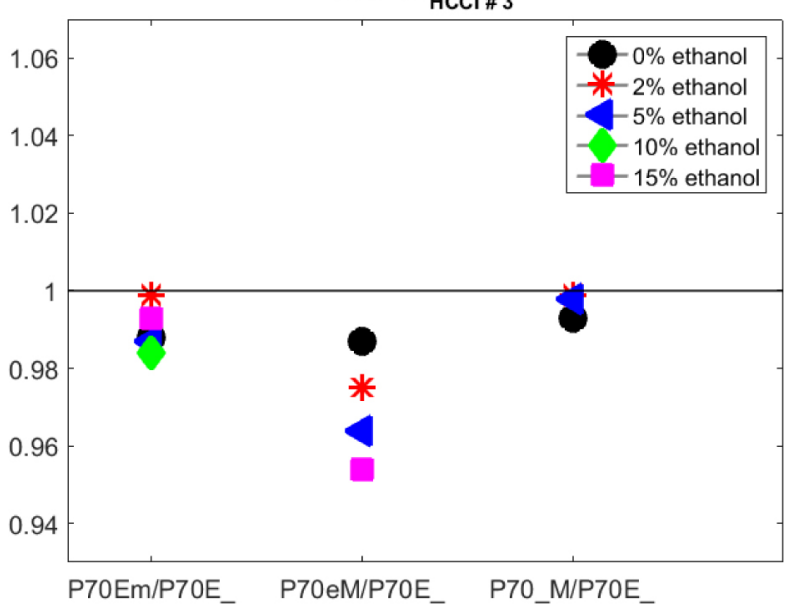

Figure A15. GEM verification for PRF 70 in HCCI mode

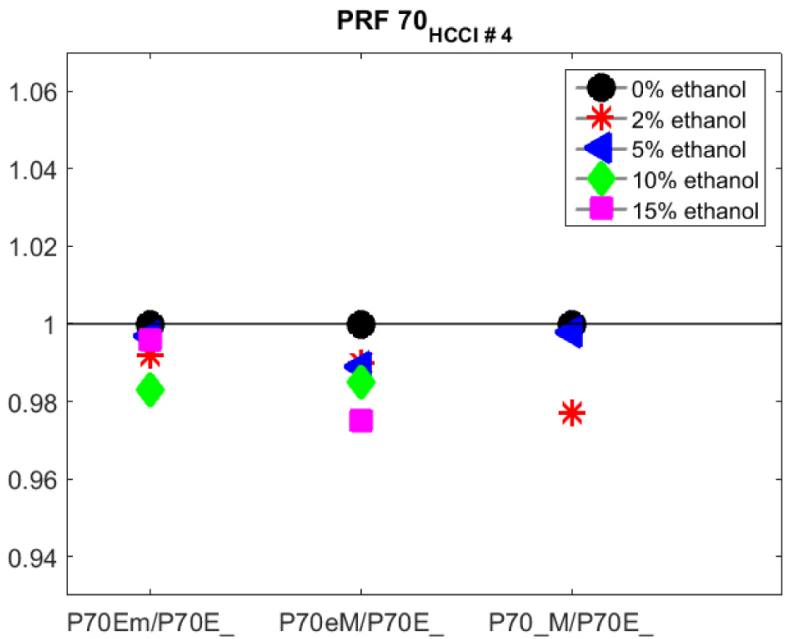

Figure A16. GEM verification for PRF 70 in HCCI mode

FACE-J ${ }_{\mathrm{HCCl} \# 1}$

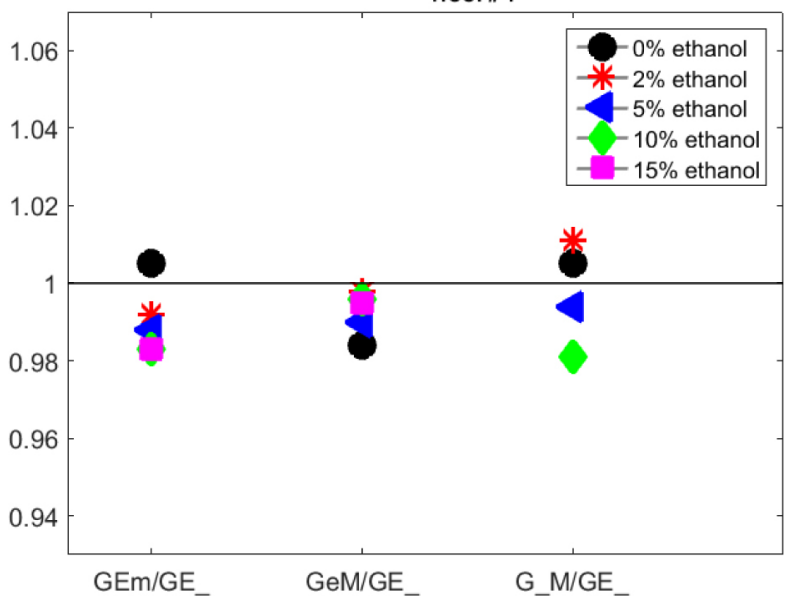

Figure A17. GEM verification for FACE J in HCCI mode 
FACE-J ${ }_{\mathrm{HCCl}}$ \#

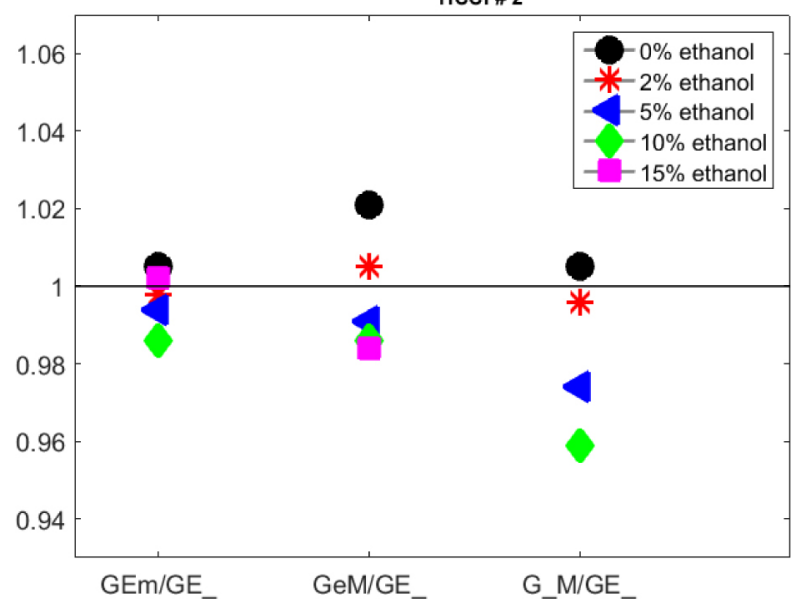

Figure A18. GEM verification for FACE J in HCCI mode

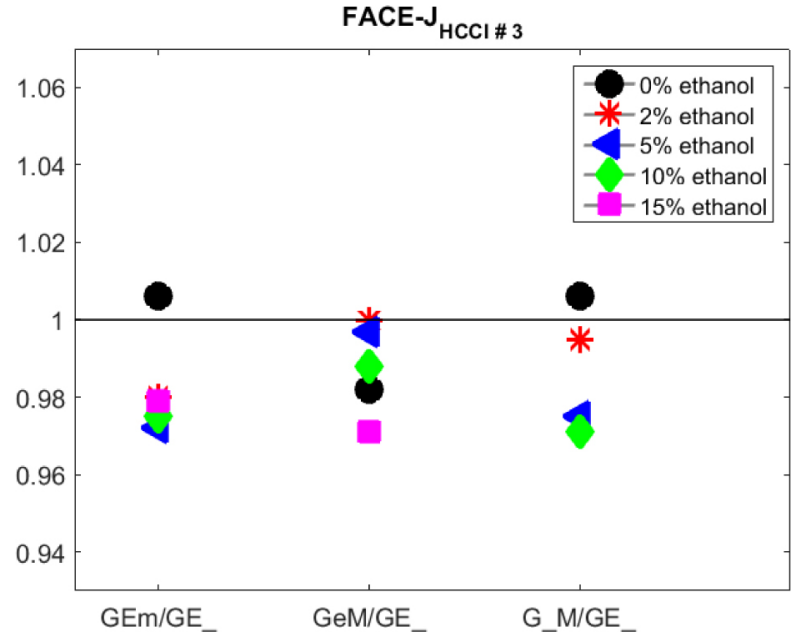

Figure A19. GEM verification for FACE J in HCCI mode

FACE-J ${ }_{\mathrm{HCCl}}$ 4

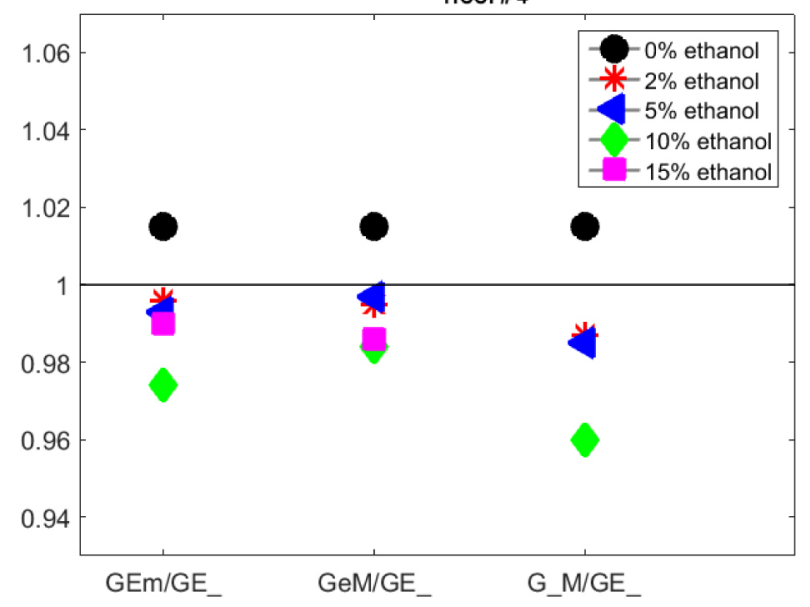

Figure A20. GEM verification for FACE J in HCCI mode
FACE-I ${ }_{\mathrm{HCCl}}$ 2

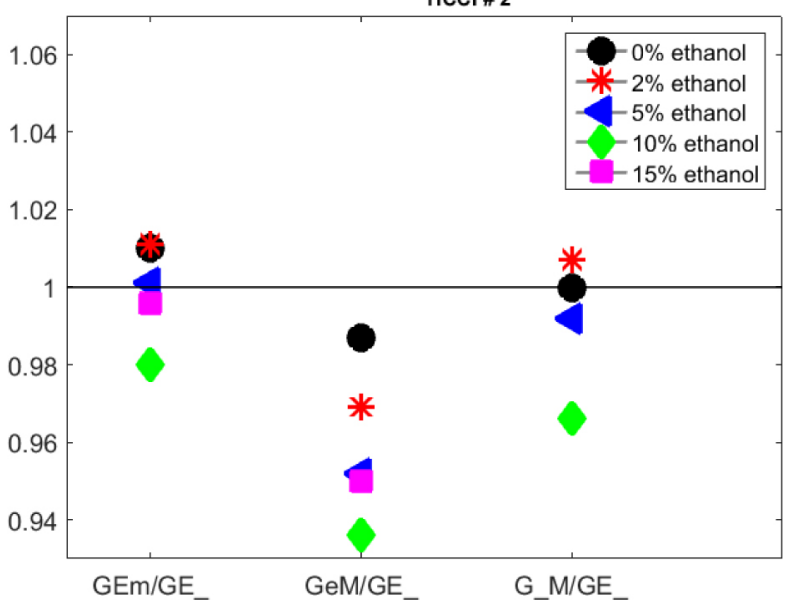

Figure A21. GEM verification for FACE I in HCCI mode

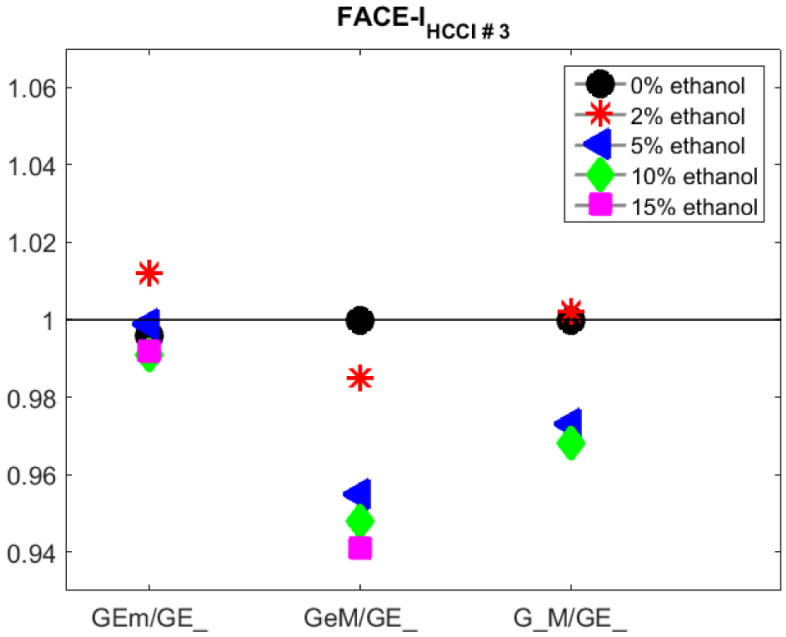

Figure A22. GEM verification for FACE I in HCCI mode

FACE-I ${ }_{\mathrm{HCCl}} \# 4$

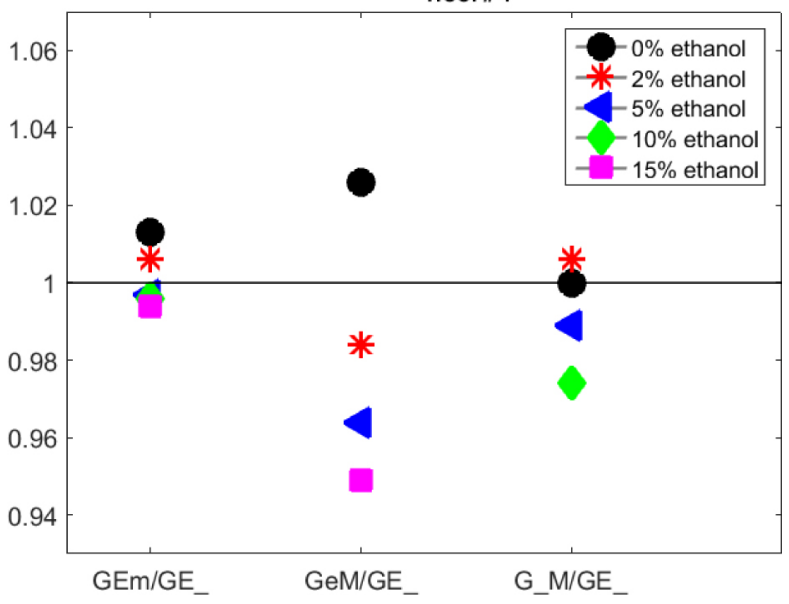

Figure A23. GEM verification for FACE I in HCCI mode 
PRF $84_{\text {SI }}$

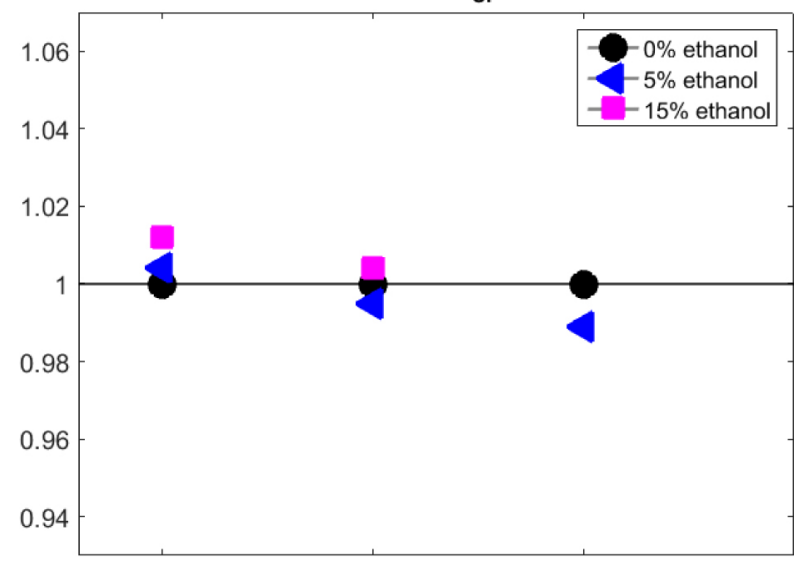

P84Em/P84E_ P84eM/P84E_ P84_M/P84E_

Figure A24. GEM verification for PRF 84 in SI mode

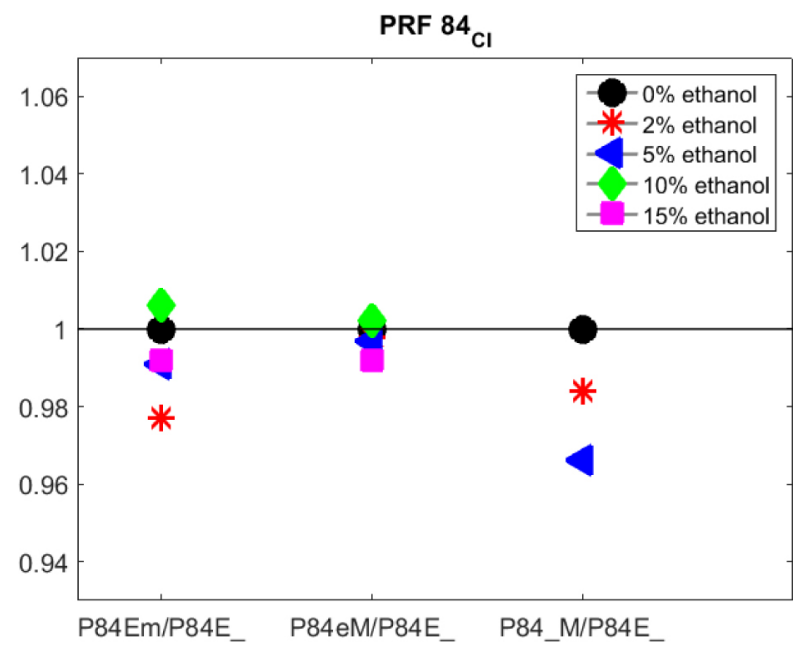

Figure A25. GEM verification for PRF 84 in CI mode

PRF $70_{\mathrm{SI}}$

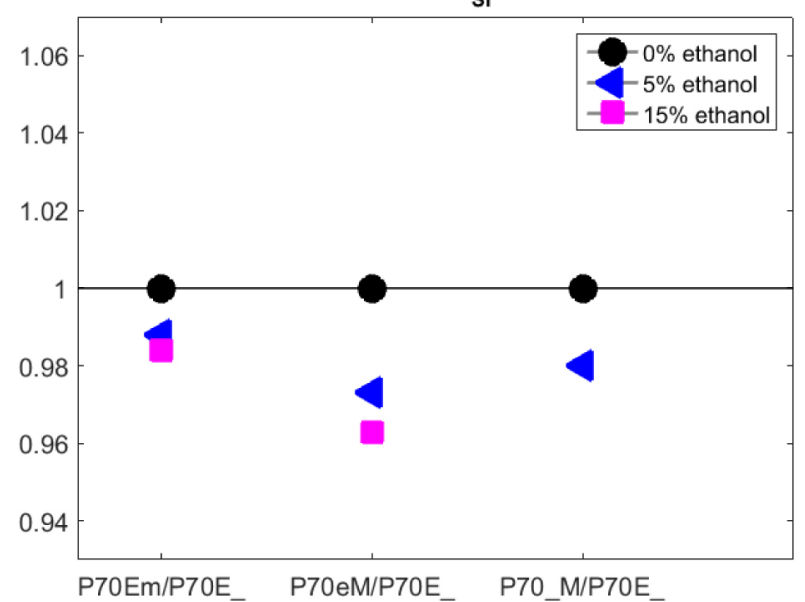

Figure A26. GEM verification for PRF 70 in SI mode
PRF $70_{\mathrm{Cl}}$

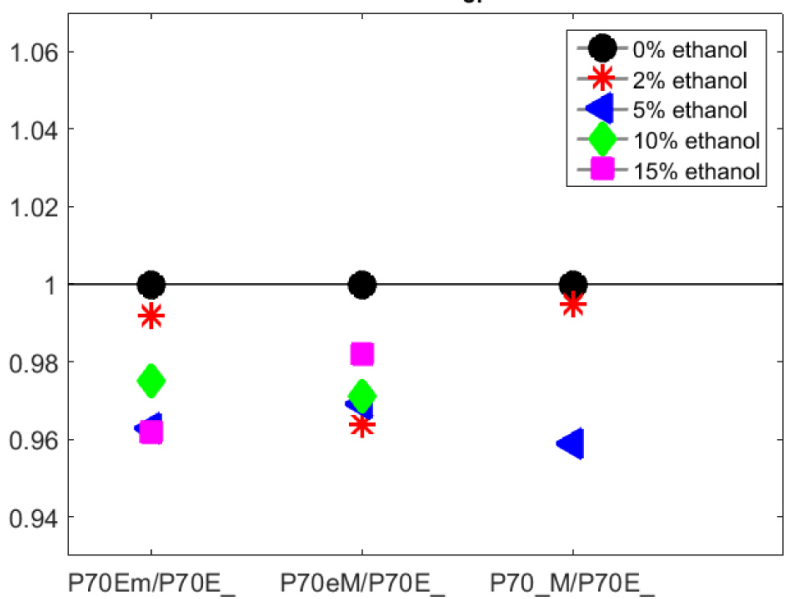

Figure A27. GEM verification for PRF 70 in CI mode

FACE-J $_{\mathrm{SI}}$

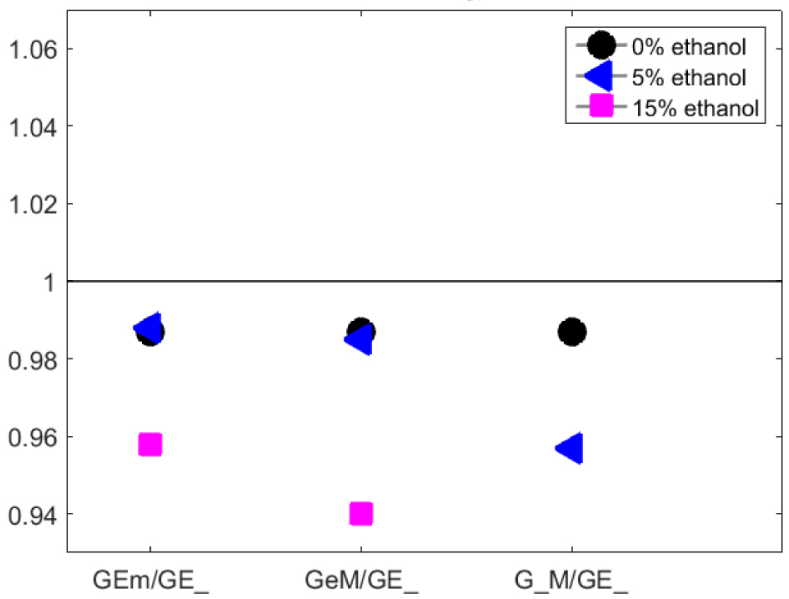

Figure A28. GEM verification for FACE J in SI mode

FACE-J ${ }_{\mathrm{CI}}$

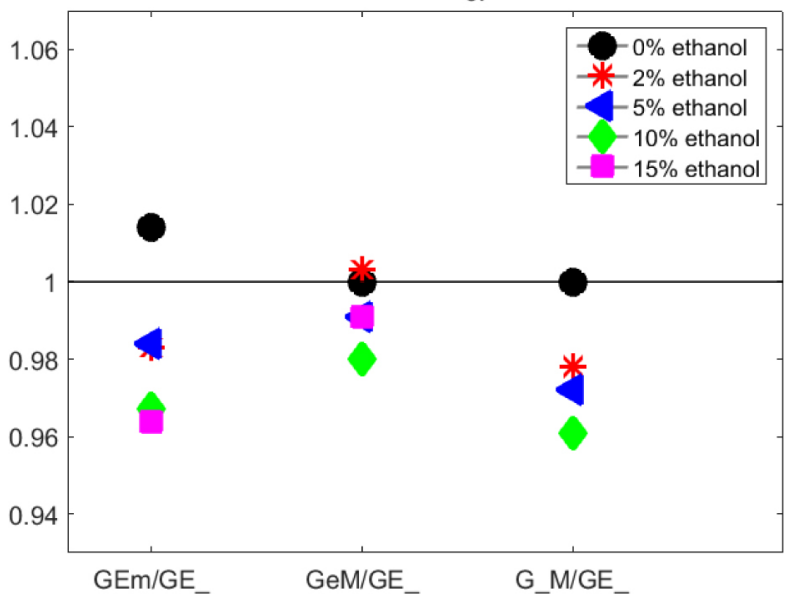

Figure A29. GEM verification for FACE J in CI mode

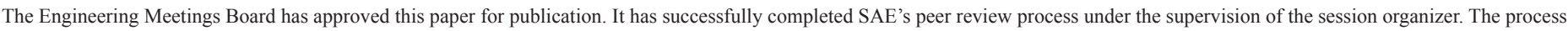
requires a minimum of three (3) reviews by industry experts.

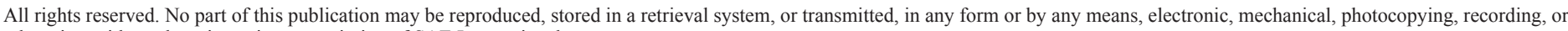
otherwise, without the prior written permission of SAE International.

Positions and opinions advanced in this paper are those of the author(s) and not necessarily those of SAE International. The author is solely responsible for the content of the paper.

ISSN 0148-7191

http://papers.sae.org/2017-01-0726 